\title{
THE EVIDENCE AND IMPACT OF ROLE CONFLICT ON COPY EDITORS WHO WORK AT COMPANIES THAT PRODUCE NEWSPAPERS AND WEBSITES
}

\author{
A Thesis presented to \\ the Faculty of the Graduate School \\ at the University of Missouri \\ In Partial Fulfillment \\ of the Requirements for the Degree \\ Master of Arts \\ by \\ GWENDOLYN L. GIRSDANSKY \\ Professor Margaret Walter, Thesis Committee Chair
}

MAY 2014 
The undersigned, appointed by the Dean of the Graduate School, have examined the thesis:

\section{THE EVIDENCE AND IMPACT OF ROLE CONFLICT ON COPY EDITORS WHO WORK AT COMPANIES THAT PRODUCE NEWSPAPERS AND WEBSITES}

Presented by Gwendolyn Girsdansky, a candidate for the degree of master of journalism, and hereby certify that, in their opinion, it is worthy of acceptance.

Professor Margaret Walter

Professor Glenn Leshner

Professor Victoria Johnson

Assistant Professor Laura Johnston 
This thesis is dedicated to my parents who instilled in me the value of education, supported me through my many ideas and loved me unconditionally. This is also dedicated to my stepparents, who did the same things. But the difference was that they didn't have to. 


\section{Acknowledgements}

Thank you Maggie Walter, Laura Johnston, Dr. Glenn Leshner and Dr. Victoria Johnston for their guidance, support and flexibility throughout the entire thesis process. Special thanks to Maggie Walter and Laura Johnston for helping me make my time at the Missourian and the Missouri School of Journalism productive and enjoyable. Also, special thank you to Dr. Leshner who helped pull me from the abyss of SPSS when I felt as if I was getting a master's in statistics and not journalism. 


\section{Table of Contents}

Acknowledgements .................................................................... ii

List of Tables ............................................................................ iv

Academic Abstract .......................................................................... viii

Chapter One: Introduction ........................................................... 1

Chapter Two: Literature Review ...................................................... 4

Chapter Three: Discussion................................................................. 14

Chapter Four: Literature Review ...................................................... 21

Chapter Five: Disc ussion ............................................................ 55

Chapter Six: Conclusion ............................................................... 64

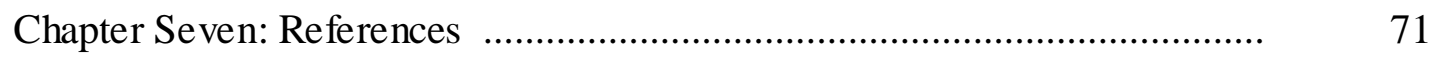

Chapter Eight: Appendix ............................................................. 73

Letter to Managing Editors ........................................................ 73

Letter to Copy Editors .................................................................

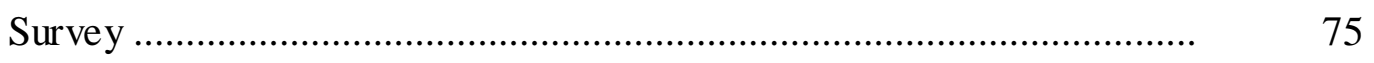




\section{List of Tables}

1. Descriptive statistics for responsibility conflict .................................. 21



3. Descriptive statistics of the number of tasks.......................................... 23

4. Frequency table for the number of tasks ................................................ 23

5. Descriptive statistics for high priority tasks ...................................... 24

6. Frequency table for high priority tasks ................................................. 24

7. Descriptive statistics percentage of high priority tasks .......................... 25

8. Descriptive statistics for satisfaction with value alignment..................... 25

9. Frequency table for satisfaction with value alignment ........................... 26

10. Descriptive statistics for regression pred icting overall job satisfaction... 29

11, Variance statistics for regression predicting overall job satisfaction....... 29

12. Significance values for regression predicting overall job satisfaction..... 30

13. Multiple regression prediction overall job satisfaction.......................... 30

14. Pearson correlation coefficients for regression prediction overall job satisfaction

15. Descriptive statistics for regression predicting frequency of pre-edit publication (with opinion and priority of traditional editing as independent variables)

16. Variance statistics for regression predicting frequency of pre-edit publication (with opinion and priority of traditional editing as independent variables) 
17. Significance values for regression predicting frequency of pre-edit publication (with opinion and priority of traditional editing as independent variables) ...

18. Multiple regression predicting for frequency of pre-edit publication (with opinion, priority of traditional editing as independent variables) ..

19. Pearson correlation coefficients for regression predicting frequency of pre-edit publication (with opinion, priority of traditional editing as independent variables)

20. Descriptive statistics for regression predicting frequency of pre-edit publication (with opinion and value of traditional editing as independent variables)

21. Variance statistics for regression predicting frequency of pre-edit publication (with opinion and value of traditional editing as independent variables)

22. Significance values for regression predicting frequency of pre-edit publication (with opinion and value of traditional editing as independent variables)

23. Multiple regression predicting frequency of pre-edit publication (with opinion and value of traditional editing as independent variables)

24. Pearson correlation coefficients for regression predicting frequency of pre-edit publication (with opinion and value of traditional editing as independent variables) 
25. Descriptive statistics for regression of number of tasks predicting responsibility conflict

26. Variance statistics for regression of number of tasks predicting responsibility conflict.

27. Significance statistics for regression of number of tasks predicting responsibility conflict

28. Multiple regression for number of tasks predicting responsibility conflict

29. Pearson correlation coefficients for regression of number of tasks predicting responsibility conflict

30. Descriptive statistics for regression of types of tasks predicting responsibility conflict

31. Variance statistics for regression of types of tasks predicting responsibility conflict

32. Significance statistics for regression of types of tasks predicting responsibility conflict

33. Multiple regression of types of tasks predicting responsibility conflict ..

34. Pearson correlation coefficients for regression of types of tasks predicting responsibility conflict.

35. Descriptive statistics for regression predicting frequency of errors

36. Variance statistics for regression predicting frequency of errors

37. Significance statistics for regression predicting frequency of errors

38. Multiple regression predicting frequency of errors 
39. Pearson correlation coefficient statistics for regression predicting

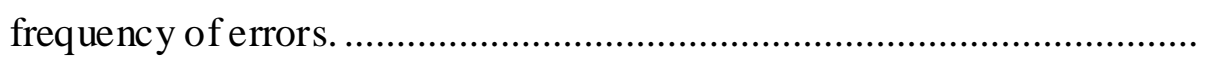




\section{Academic Abstract}

The newspaper industry has faced colossal shifts over the past several decades because of the Information Age and changing needs of readership. Copy editors have been among the most affected as the newsroom seeks to adapt. These editors have had an increasing number of responsibilities divided among fewer people.

This study predicted that copy editors have experienced role conflict, which would manifest itself as job satisfaction and responsibility conflict. A questionnaire was developed in Qualtrics and sent out through the American Copy Editors Society as well as directly to managing editors and copy editors.

Analysis found that most copy editors' responsibilities conflict at least part of the time - not only against deadline, but against one another. The number of tasks copy editors have is a predictor for the frequency of responsibility conflict. Social media, website management, and page proofs are three of the tasks copy editors might have that are moderately correlated with the frequency of role conflict. It might be best to have one person focus on those types of tasks, which would allow all of the other editors take on tasks that require longer, in-depth tasks, rather than have all the editors be perpetually distracted.

Analysis also found that the alignment of copy editors' values with those of the company were more highly correlated than any other satisfaction variable, including salary, shifts, and co-workers. Therefore, it might be beneficial to work to communicate why and how the company's values developed into its current standards. 


\section{Introduction}

The ability to operate quickly, efficiently, and accurately under pressure has always been a requirement of all newsroom staff. For the copy editor, that traditionally meant editing copy for clarity, style, accuracy, and grammar as well as withholding stories that were not fit for print while on deadline. For more than a century, copy editors walked on the tightrope between quality and time constraints, caught between the whims of reporters and the constant encroaching deadlines. While copy editors are trained to work well on deadline, there has generally been a perceived inherent negative correlation between quality and time.

But the status quo couldn't go on forever. The Information Age acted as a disruptor to the print model. Soon, newsrooms were hemorrhaging funds and reducing staff sizes to compensate. The Reynolds Journalism Institute research shows that more than three-quarters of newsrooms cut at least 10 percent of their staff. Even now, many places are making deeper cuts despite recent research from RJI that indicates cutting staff hurts profitability more than saving the budget. Jim Romenesko and the American Society of Copy Editors reported in November 2013 that the Lincoln Star Journal was cutting its entire copy desk, though the editors were given the option to work at a centralized hub. Romenesko reported at the end of February 2014 that the Tampa Bay Tribune announced deep staffing cuts, most specifically at the copy desk. Those with design skills were more likely to keep their jobs. Multi-faceted editors have grown in numbers and desirability as newsrooms have strived to make a digital-first model 
profitable. Newspapers have been using new media to attract readers to the websites to increase value of a subscription and advertising.

New media means new responsibilities - many of which have landed on the copy desk at a time when there are fewer people there to handle it. As those clearly defined roles essentially evaporated, the copy desk began to experience role change, a faction of role theory. As the tasks began to mount, it seems to have developed into role conflict and role ambiguity, other factions of role theory. These multifaceted editors have tasks that ks include social media, apps and aggregations, to name a few. The attention given to posting social media to promote stories to the readership, which of course has value, is attention taken away from traditional copy editing. Traditional copy editing, looked at another way, is quality assurance. It is often these copy editors who are the last advocates for the reader in the newsroom, and the attention they give to stories is essential to ensure a quality product. With too many tasks, the product's or products' overall quality decreases. However, it was not only the number of tasks that contribute to role conflict. It's the types of tasks. Those that the demand immediate attention at the drop of a dime, or rather at the whim of breaking news, force copy editors to multitask and bounce between responsibilities. It breaks concentration, which can be damaging when copy editors are looking at the overall structure or tone of a piece. It might also divert enough attention that copy editors spot see a recurring pattern in a story.

The digital age has changed the mindset of the newsroom from expecting a deadline at the end of the cycle to having a deadline during every minute of every day.The 24-hour news cycle that television was becoming accustomed to broke into the print newsroom. The balance between quality and time was demolished. It also affected 
the structure of the newsroom. While once most newspapers had nearly identical workflows and timelines, the digital era caused divisions. Over time, these divisions have become more and more divergent. Now, some job titles in one newspaper might not even exist in another - or those responsibilities might appear under a different title. The same title might mean a completely different set of responsibilities. Reporters might have to shoot their own photographs at one paper but not at another. But their principle responsibility is to write an article.

However, copy editors are more likely experience the lack of role consensus particularly acutely. Some might work only online at one paper, editing local content for the Web immediately and managing the website, while another might be pulling wire stories and designing print pages, without time to edit. Therefore, no quantitative study can take into account all of the ways newsrooms have coped with the economic strains. But this study looks to explore the modern copy editor at daily newspapers in the United States under the framework of role theory. 


\section{Literature Review}

Society is built upon the premise that people fulfill a set of roles, demonstrated through the various tasks they complete, which allows the social machine to function, according to B.J. Biddle (1986). For example, there are parental roles such as mother or father, which are parts of the familial unit, and there are gender roles such as female or male. These are concepts identified in role theory: a compilation of explanations about socially defined roles. However, these are not limited to society because these roles also appear in the workplace as organization-related identities (Thatcher \& Zhu, 2006), henceforth referred to simply as roles. Much of the focus of role theory has been placed on these broad roles and when they come in conflict with each other. This study will expand the research from inter-role conflict or the conflict among several general roles into intra-role conflict, which is the disagreement among sub-roles of one broad role. Biddle (1986) recommends using role conflict with caution because there was no substantive research into how frequently it appears. This will provide some research into its frequency, which will provide some basis of comparison in the future.

A newspaper's newsroom has reporters who could be considered content producers, displayed through their tasks of reporting and writing. City editors might be viewed as the delegators because they assign stories and decide when to pass articles through to the copy desk, which is its own beast. The copy desk can trace its roots back to the nineteenth century (Keith, 2005), and after a hundred years it comprised about 1/5 of the newsroom's force (Russial, 1998). Allan Bell (1991) and Brian Brooks (2008) write that copy editing serves four main functions: cutting, clarifying, standardizing language and maximizing news value. For the first century, this traditional copy editing 
constituted the bulk of the copy editor's responsibilities. Other duties mainly dealt with pulling stories and photos from wire services. In this frame, traditionally, copy editors often fulfilled the roles of gatekeepers, quality assurance experts, and reader advocates within the newsroom _ filling a trifecta of roles.

These roles were similar from newspaper to newspaper, which allowed for a role consensus or mutual agreement of the expectations (Biddle, 1986) of the copy editor among newspaper organizations. However, since the 1980s, the expectations of the copy desk have been swinging wildly, and a cohesive definition of the copy editor no longer exists in a strict sense. The copy desk also was at risk of facing extinction during the 1990s but recuperated just enough to migrate toward centralized copy and design desks. Copy editors have been lumped with layout editors and online producers and then separated again by the American Society of Newspaper Editors (ASNE, 2013). Richard Hilbert (1981) compares roles to the positions of a football team and that all the roles work together to create an effective team. The same type of teamwork happens in the newsroom. However, that might have been derailed when the decline of the newspaper industry resulted in the loss of thousands of jobs. In 1989, there were 57,000 employed in the U.S. newspaper industry; by 2011 that had dropped to 41,000 (Jarvis, 2012). Many of those job losses occurred in the copy editing sector; for example, the Philadelphia Inquirer went from 60 copy editors in 2005 to 23 in 2012 (Fidler, 2012). The entire copy desk at the Lincoln Journal Star was laid off in late 2013, but editors were given the option of joining a centralized design hub, according to the American Copy Editors Society and reported by Jim Romenesko (2013). 
Hilbert's analogous football team could begin seeing role conflict, and, therefore, disaster if half the team got cut. The quarterback might also be the wide receiver. But that doesn't work because it would be impossible for him to throw the football from the 50yard line to himself in the end zone. Something similar happened in the newsroom as staff has been reduced. For example, the loss of copy editors meant the same number of responsibilities was divided among fewer people, and in some cases there were even more responsibilities given the advent of the digital age. Even if the copy desk stayed steadily staffed the editors might have to pick up responsibilities of other newsroom departments that were downsized, but which departments were downsized were not specified. Page design and production has become a significant part of copy editor responsibilities (Jarvis, 2012). As a result, the copy desk and the copy editor are in the midst of a massive role change as they acquire a set of new responsibilities that have drifted over from other departments or that have arisen as a result of the digital publication.

Role change, like role ambiguity, role clarity, role consensus and role conflict, falls under the umbrella of role theory. Faucett, et al., (2012) write that historically role conflict and role ambiguity have independently impacted job satisfaction; however, recent research indicates they might interact to cause dissatisfaction and role stress. All of these, but particularly role conflict, pertain to the limbo copy editors currently find themselves in. Ralph Turner (1990) writes "role change can be defined as a change in the shared conception and execution of typical role performance and role boundaries." Role conflict and ambiguity are assumed to negatively affect job satisfaction and job 
involvement in role theory (Kemery, 2006). But role conflict began long before the downturn of the economy and loss of revenue for newspapers.

\section{Digital Pagination}

The consensus that defined the copy editor role began to break apart and role change began to snowball with the advent of the Information Age. Pagination and digital layout might have been the first substantive instance of role conflict for copy editors in the newsroom, where two or more tasks conflict and which appears when there is the concurrent appearance of incompatible responsibility for the person to complete. Role conflict frequently occurs between two types of roles, mother and employee for instance. However, the roles that fall under the umbrella of "copy editor" were competing with one another. "Role theory states that, when the behaviors expected of an individual are inconsistent - one kind of role conflict - he will experience stress, become dissatisfied, and perform less effectively than if the expectations imposed on him did not conflict," write John Rizzo, et al, (1970). Susan Keith (2005) wrote about her 2002 survey in "Copy editor job satisfaction lowest at small newspapers," which dealt with one aspect of role conflict: satisfaction. Her research indicated copy editors were particularly dissatisfied with their jobs at small newspapers. However, her discussion section attributed most of the complaints to the salary restrictions and the lack of advancement opportunities at newspapers with circulations between 25,000 and 50,000.

Digital pagination became routine in most newsrooms and, fairly early on, split the time of the copy desk. Keith (2005) writes in "Newspaper Copy Editors Perceptions of Ideal and Real Ethical Roles" that 
"Perhaps the most significant technological change was the introduction in the 1980s and 1990s of electronic pagination, which shifted page makeup responsibilities from composing room staffs to copy editors. It gave editors greater control over page appearance but also cut into the time copy editors had for substantive editing."

This divided the attention of the copy editors in several ways. Not only were they quality assurance experts completing traditional copy editing, but they became packagers of the product, which required a different style of thinking.

The yearly census data from the American Society of News Editors was indicative of the link between the two jobs. From 1998 through 2006, there was a category of "copy editors/layout editors," and during that time there was a fairly steady number of copy editors/layout editors (American Society of News Editors, 2008). A 2006 survey by C. Max Magee at Medill School of Journalism at Northwestern University found newsroom managers were aware they needed staff who would not be affected by role conflict. His survey found "attention to detail, ability to work under time pressure, multitasking ability and teamwork were universally important" to newsroom supervisors.

The next major role change occurred during the last decade of the twentieth century when copy editors were perceived as expendable. Copy desks were under the immediate threat of extinction due to a variety of factors (Keith, 2005). Vicki Smith (1997) writes in "New Forms of Work Organization" that for one, there had been an uprising of the "flexible work model" since the 1970s, which sought to break away from the postwar assembly-line method. The flexible work model aimed to increase employee initiative and engagement. It also allowed employers to add in flexibility to the system by 
relaxing "rigid bureaucracies" and trimming "excessive use of organizational resources" (Smith 1997). The system also allowed for easily adjusted workflows, allowing people to share, overlap, or exchange responsibilities based on the needs of the day or trends in the industry. In the newsrooms, supervisors felt reporters and city editors could absorb the job responsibilities of the copy editors and, therefore, the copy desk was expendable.

However, just as extinction was becoming a distinct possibility for copy editors, the Information Age began to take a firm hold. Between 1998 and 2007, when ASNE grouped copy editors and layout editors together (ASNE, 2013), more newspaper organizations began experimenting with websites, and as the technology developed into content management systems, the day-to-day responsibilities shifted away from information technology departments to the newsroom, specifically the copy desk, thus dividing the attention of many copy desks into three focuses, traditional copy editing, print production, and Web production, and further deepening the role conflict. John Russial (1998) wrote in "Goodbye Copy Desks" that "a fundamental idea is that computerization can make it possible for employees to handle a much wider range of tasks." As a result, copy editors had to become good at many different tasks rather than experts on something specific - such as traditional copy editing tasks of grammar, style, and the five C's: clarity, correctness, conciseness, comprehensibility, consistency. "Many successful re-engineering efforts follow that pattern - they enable companies to add value more quickly by turning specialists into generalists" (Russial, 1998).

Again, ASNE recognized the trend of changing copy editor responsibilities and transitioned in 2007 to include "online producers" in the job listing category. There was an uptick in numbers of copy editors, probably to include the online producers. From 
2007 onward, the number of people in the "copy editors/layout editor/online producer" category steadily declined, until there were about 3,000 fewer people working in that category in 2011 (ASNE, 2013).

\section{Content management systems}

Soon website management, social media, and aggregation also became some copy editors' job. With the unlimited amount of space the Web offers, gatekeeping became less crucial (Singer, 2006). More stories that would even remotely interest the audience were able to be published online. Yet, for many publications, editing copy and editing online stories was not necessarily within the new job description of copy editors. A 2007 survey of 155 American newspapers revealed that 15 percent did not copy edit stories for online (Russial, 2009). One of the reasons is that speed is often a matter of utmost importance, and Russial (2009) wrote in "Copy Editing Not Great Priority For Online Stories" that "longstanding work schedules designed for print-edition publication make it difficult to have breaking news edited" by copy editors. For 15 percent of publications, that meant the copy of their website was not being handled by copy editors who were trained to spot style and grammar errors as well as accuracy problems, which meant the quality wasn't being assured. For the other 85 percent of newspapers, copy editors were not only on the singular print deadline at the end of the night but on "as soon as possible" deadlines. Each story had its own immediacy.

One key observation to make is that Russial surveyed newspapers with a circulation size of more than 30,000 . He writes that smaller newspapers have an entirely different structure and different organizational method for copy desks, which is why they were not included. The survey also found that newspapers were beginning to adjust the 
work hours for copy editors to earlier in the day so trained copy editors could edit online content. (Russial, 2009) There has also been a move toward centralization, the use of one desk to complete work, such as design or editing, for a variety of newspapers. Gatehouse Media has moved toward centralization, and "design and copy editing for the Tribune Co. properties, the Hartford Courant and the Daily Press in Newport, Va., are handled in Chicago" (Fidler, 2012). McClatchy and BH News Media have also migrated toward hubs as well.

Carl Sessions Stepp (2009) writes about the St. Louis Post Dispatch in "The Quality Control Quandary.” He spoke with a 10-year copy desk veteran at the PostDispatch who said that the editors are constantly somewhere between "comfortably rushed" and "always having to railroad stuff." Stepp also reports that there are seven people doing the work previously completed by 12 people, which has reduced the number of eyes on each piece of copy. In fact, there is a high burnout rate among young copy editors, even higher than among older copy editors. Often young copy editors find their job is much different than what they expected. (Reinardy, 2011) This indicates that the common perception of what a copy editor does is no longer the reality. He also found that there were "high levels of emotional exhaustion and depersonalization among copy editors at the Daily Oklahoman" and that they tend to be more cynical than managing editors. In fact, one young copy editor writes that there "were not enough co-workers on the copy desk, city desk or sports desks to help read and design.” (Reinardy, 2011) This immediately indicates their attention is divided at least among editing, designing, and proofing, under an impending deadline without enough support. This isn't even taking into consideration other duties such as publishing stories and photos for the Web, as well 
as creating, posting, and scheduling social media. They also need to check how that content looks on apps, tablet devices, and phones.

Such divided attention is a prime example of Randall Schuler's definition of conflict. Schuler (1977) writes in "The Effects of Role Perceptions on Employee Satisfaction and Performance Moderated by Employee Ability" that people experience role conflict when they are placed in "a situation in which an employee was confronted with a set of two or more demands such that compliance with one demand made compliance with the other demand(s) difficult or impossible." Travis Tubre and Judith Collins (2000) say that role conflict occurs when people cannot do every task expected. It has reached a point that for many copy editors their tasks are not merely competing but conflicting to the extent that they can't do everything that is expected even at a basic level.

T.C. Tubre and J.M. Collins (2000) found that there was a slightly higher correlation between role conflict in professional jobs, examples of which were not specified, and job performance than with other types of positions such as managers. However, they did not indicate how extreme the role conflict was in their respondents. Vincent Onyemah (2008) found that a moderate level of role conflict on salesmen is beneficial to job performance; however, too much and it has a negative effect. If this study finds that the copy editors show a strong correlation between role conflict and job performance, then it would be a strong indicator of how severe role conflict is in the position.

According to Keith (2005b), there has historically been a lack of unity among copy editors. The brotherhood that exists among reporters never really took hold in copy 
editors. Keith (2005b) writes "they (copy editors) do not have a great deal of autonomy, they do not have a separate ethics code, and they did not have an association until the American Copy Editors Society was founded in 1996." The lack of unity was prevalent even before the job responsibilities began to diverge.

As this literature has shown, there has been a growing gap between the historic copy editor and the modern copy editor, even the cohesive definition of "copy editor" has begun to erode. But there is little research that talks about the responsibilities of the modern copy editor. The hypotheses of this thesis look to examine the responsibilities, values, and priorities of the modern copy editor. 


\section{Method}

Research design: Surveys are frequently used in the media industry. For example, The American Society of News Editors creates an annual census based on a survey of its members to gain an understanding of industry trends. The data ASNE collects asking about the number of minorities and the number of people in different job titles: "copy editor/layout editor," "reporter," and "editor," as well as the number of minorities (ASNE, 2013). However, these studies look more toward the organization as a whole, rather than the thoughts and experiences of people working there.

Susan Keith (2005), who is among the leaders of copy editor research, has also used surveys. Some research has focused on ethics of copy editors and their job satisfaction. In 2002, she conducted a survey with 79 questions of copy editors at newspapers with a daily circulation of 25,000 or more and offered the copy editors the option of either submitting the survey online or via mail.

Since email has become more prominent and widespread since 2002, respondents to this survey only had the option of responding online.

Testing instrument: The questionnaire was created through the website Qualtrics. The researcher chose 13 tasks that might frequently appear on the copy desk based on a literature review and adjusted after the pre-test: aggregation projects, app updating, copy editing local stories, copy editing stories from wire services, print layout and design, online photo caption/photo gallery editing, page proof editing, pulling stories and/or photos from wire services, traditional copy editing, posting social media, writing online headlines and writing print headlines. It should be noted that editing local and wire 
stories are parts of traditional editing. The questionnaire first asked copy editors about how much time and effort they put into each task in proportion to the other tasks based on a 11-point scale, from 0 (none) if it was not part of the responsibilities to 10 (a lot). Of the tasks that were included in their responsibilities, they were asked how much they value each task, how they prioritize each task among their other tasks, and how well they complete each of their tasks, also all on 11-point scales.

The researcher also took into consideration Rizzo, et. al.'s, questionnaire regarding role conflict and role ambiguity in complex organizations. However, that questionnaire was formed more than 40 years ago, has faced scrutiny since, and was not tailored toward the media industry. Therefore those questions were adapted for the purposes of this survey. For instance, among the questions were "I perform work that suits my values," "I know what my job responsibilities are," and "I work under incompatible policies and guidelines." Those appeared in this survey under how different factors contribute to job satisfaction or dissatisfaction: "Your values match company values," "Understanding job expectations," and "Agreement among job expectations." Another of Rizzo's questionnaire items was 'I receive incompatible requests from two or more people," which appeared in this questionnaire as "How frequently, if ever, do others in the newsroom ask you to complete tasks that are in conflict with your normal responsibilities?"

Participants: The original survey sample was copy editors who work at newspapers that publish a website and a daily newspaper with a circulation of 20,000 or more. However, after a week, to increase sample size, the newspaper circulation size requirement was decreased to include newspapers with 15,000 or more. In total, there 
were 377 respondents. Of those, 93 were excluded because they did not finish the survey. Another 21 were excluded for various reasons including: working for radio, magazine, online class sites, or journals, among others. The total sample size was 263.

Descriptive statistics were calculated to determine the breakdown of the respondents' demographics. The mean age for a copy editor was almost 42 years old (SD $=13.456)$, and in the industry for 18.76 years $(S D=12.651)$, a copy editor for 14.56 years, and at their job for 8.82 years $(S D=10.525)$. The mode for education is the bachelor's degree: 201 earned a bachelor's, 40 a master's degree, and 3 a doctorate. There was an almost even split in gender, 128 respondents were male and 129 were female. Not every respondent answered the question.

Procedure: A questionnaire was developed through the website Qualtrics. A pretest was given to members of the copy desk at the Columbia Missourian, where the researcher worked and would've been excluded from the finalized survey because of conflict of interest concerns. The seven pre-test respondents from the Missourian completed the survey based on experiences at the Missourian or another news outlet at which they worked or interned. After minor adjustments to the survey were made, a link to the survey was sent out via email to members of the American Society of Copy Editors. The initial email said the survey was for members who were copy editors at companies that published websites and had a daily circulation of more than 20,000 . Additionally, individual emails were sent to executive editors, managing editors, or copy desk chiefs at newspapers with a circulation of more than 20,000 , and they were asked to send the survey on to their copy desk staff. 
After the first week the survey was open, the researcher decided to increase the sample size by decreasing the necessary circulation size to 15,000 . A reminder email was sent to ACES members, which noted the decreased circulation requirement. A new round of emails was sent out to executive editors, managing editors, or copy desk chiefs at the new sample size. The researcher looked to identify specific copy editors at newspapers that did not have respondents and worked to contact them directly. The survey was officially open for two weeks. Respondents completed the survey within a week after it officially closed. Once the survey was closed, multiple linear regressions were run.

The next section discusses the controls, variables that were used for the regressions as well as the hypotheses the regressions tested.

\section{Controls}

Age: The age of the respondent in years.

Gender: The gender of the respondent.

Education: The highest level of education the respondent achieved.

Job length: The length of time the respondent had held their current position.

Copy editor length: The number of years the respondent had been a copy editor.

Industry length: The number of years the respondent had been in the media.

\section{Independent Variables}

Satisfaction variables: Copy editors indicated how several items contributed to their overall job satisfaction. Each of the following is a satisfaction variable: salary, shift hours, co-workers, feeling as if they did good job, variety of tasks, presenting accurate and clear information to readers, agreement among job expectations, understanding job 
expectations, ability to meet expectations, and how their values match the company's values. All 10 items were used during the analysis.

Responsibility variables: Copy editors indicated how much several tasks were a part of their responsibility. Each of the following is a responsibility variable: aggregation projects, app updating, copy editing local stories, copy editing wire stories, print layout and design, online photo caption and/or photo gallery editing, page proof editing, pulling stories and/or photos from wire services, traditional copy editing, website management, writing and posting social media, writing online headlines, and writing print headlines. All responsibility variables were used during analysis. The response scale was 0 to 10.0 is 'none', 10 is 'a lot.'

Number of tasks: The variable was calculated by adding up the number of tasks copy editors indicated were part of their responsibility.

Priority variables: Copy editors indicated how they prioritized traditional copy editing on a scale of $0-10$ : 0 is very low priority, 10 is extremely high priority.

High-priority tasks: The variable was calculated by adding up the number of tasks copy editors indicated were prioritized as an 8, 9 or 10 (scale: 0 very low priority, 10 , extremely high priority).

Percentage of high-priority tasks: The variable was calculated by dividing the number of high priority tasks by the number of tasks and then multiplying by 100 .

Value variables: Copy editors indicated how they traditional copy editing on a scale of 0 to 10.0 was a very low value and 10 is a very high value. 
Opinion of pre-edit publication: Copy editors indicated how frequently they think a story should be published online before editing on a scale of 0 to 10.0 was "never" and 10 is "always."

\section{Dependent Variables}

Frequency of responsibility conflict: The amount copy editors indicate they experience conflict between responsibilities on a scale of 0 to 10.0 was 'never' and 10 was 'all the time.'

Overall job satisfaction: How satisfied copy editors indicate they are with their jobs on a scale of 0 to 10.0 was 'extremely dissatisfied' and 10 was 'extremely satisfied.' Pre-edit publication: How frequently copy editors indicate they publish articles online before editing on a scale of 0 to 10.0 was 'never' and 10 was 'all the time.'

Frequency of errors: How frequently they feel they miss errors as a result of time constraints or responsibility conflict on a scale of 0 to 10.0 was 'never' and 10 was 'all the time'

\section{Hypotheses}

Hypothesis 1: Copy editors' satisfaction of how their values align with those of the company is the leading predictor of job satisfaction.

Hypothesis 2: Other leading predictors of job satisfaction are those indicative of role conflict or role ambiguity.

Hypothesis 3: How copy editors prioritize copy editing and the frequency at which he or she indicates stories can be published online predict the frequency they do publish stories online prior to editing. 
Hypothesis 4: The respondents' value of traditional copy editing and respondents' opinion of publishing stories before editing has a negative relationship with how frequently stories are published online before editing.

Hypothesis 5: The frequency that copy editors indicate responsibilities conflict for time/attention is positively correlated with the number of tasks copy editors indicate are part of their responsibility and the number of tasks copy editors indicate are high priority.

Hypothesis 6 . There is a correlation between the frequency copy editors indicate responsibilities conflict and the types of tasks copy editors indicate take up large portions of their responsibilities. (A hypothesis pertaining to which tasks will impact frequency of conflict cannot be formed).

Hypothesis 7: The frequency of responsibility conflict, the number of tasks, and the frequency of enough time to complete tasks predict the frequency of errors. 


\section{Results}

Descriptive statistics were calculated to determine how frequently copy editors indicate they experience role conflict. The data indicate that copy editors experience responsibility conflict, on average, half of the time $(M=4.98, S D=2.57$; Table 1$)$. Respondents most frequently indicated they thought their responsibilities rarely conflicted $($ Mode $=3$; Table 1).

Table 1:

Descriptive statistics for responsibility conflict

\begin{tabular}{llllll}
\hline & Mode & Mean & Std. Deviation & Statistic & Std. Error \\
\cline { 5 - 6 } & & & & & .247 \\
\hline Conflict & 3 & 4.98 & .2572 & .154 \\
\hline
\end{tabular}

Note. $\mathrm{n}=249 ;$ Note. Those who did not respond were excluded.

Frequency tables were calculated to find the breakdown of responses. On a scale of " 0 " (or never) to "10" or always, the data indicated that 30 percent of copy editors experienced responsibility conflict between a 6 and 10 on the scale, and that 50 percent of copy editors experienced responsibility conflict between 5 and 10 on the scale (Table 2). Because only seven respondents never experienced responsibility conflict, 97 percent of respondents indicated they experienced some level of responsibility conflict. 
Table 2:

Frequency table for responsibility conflict

\begin{tabular}{llrrrr}
\hline & & Frequency & Percent & Valid Percent & Cumulative Percent \\
\hline & 0 & 7 & 2.7 & 2.8 & 2.8 \\
& 1 & 12 & 4.6 & 4.8 & 7.6 \\
& 2 & 22 & 8.4 & 8.8 & 16.5 \\
& 3 & 39 & 14.8 & 15.7 & 32.1 \\
& 4 & 36 & 13.7 & 14.5 & 46.6 \\
Valid & 5 & 38 & 14.4 & 15.3 & 61.8 \\
& 6 & 19 & 7.2 & 7.6 & 69.5 \\
& 7 & 34 & 12.9 & 13.7 & 83.1 \\
& 8 & 15 & 5.7 & 6.0 & 89.2 \\
& 9 & 9 & 3.4 & 3.6 & 92.8 \\
& 10 & 18 & 6.8 & 7.2 & 100.0 \\
Missing & System & 249 & 94.7 & 100.0 & \\
\hline & & 14 & 5.3 & & \\
\hline
\end{tabular}

Note. Those who did not respond were excluded.

Descriptive and frequency statistics were also calculated to determine how many responsibilities copy editors had. Out of the 13 choices, respondents indicated that, on average, respondents have 9 tasks to complete during each shift $(M=8.84, S D=2.298$; Table 3). Copy editors most frequently indicated they had 7 tasks to complete (Table 3) and more than a quarter of respondents had at least 10 responsibilities (Table 4). 
Table 3:

Descriptive statistics for the number of tasks

\begin{tabular}{llllll}
\hline & \multirow{2}{*}{ Mode } & Mean & Std. Deviation & \multicolumn{2}{c}{ Skewness } \\
\cline { 5 - 6 } & & & & & \\
& 7 & 8.84 & 2.298 & -.214 & .150 \\
\hline No. of Tasks & 7 & &
\end{tabular}

Note. $\mathrm{N}=263$

Table 4:

Frequency table for the number of tasks

\begin{tabular}{|c|c|c|c|c|c|}
\hline & & Frequency & Percent & Valid Percent & Cumulative Percent \\
\hline \multirow{12}{*}{ Valid } & 3 & 4 & 1.5 & 1.5 & 1.5 \\
\hline & 4 & 1 & .4 & .4 & 1.9 \\
\hline & 5 & 14 & 5.3 & 5.3 & 7.2 \\
\hline & 6 & 23 & 8.7 & 8.7 & 16.0 \\
\hline & 7 & 48 & 18.3 & 18.3 & 34.2 \\
\hline & 8 & 28 & 10.6 & 10.6 & 44.9 \\
\hline & 9 & 26 & 9.9 & 9.9 & 54.8 \\
\hline & 10 & 45 & 17.1 & 17.1 & 71.9 \\
\hline & 11 & 38 & 14.4 & 14.4 & 86.3 \\
\hline & 12 & 29 & 11.0 & 11.0 & 97.3 \\
\hline & 13 & 7 & 2.7 & 2.7 & 100.0 \\
\hline & Total & 263 & 100.0 & 100.0 & \\
\hline
\end{tabular}

Descriptive and frequency statistics were calculated to determine how many responsibilities were of high priority. The data indicate that almost half of the responsibilities copy editors say they have are high priority $(M=4.63, S D=1.89$; Table 7). Copy editors most frequently indicated they had five high priority tasks (Table 5), and there were very few people who said they had more than 9 high priority responsibilities out of the 13 options (Table 6). A descriptive statistic was also calculated for the percentage of high priority tasks. Additional descriptive statistics were calculated to find 
out how many tasks were high priority. The data indicate that, on average, half of a copy editor's tasks are high priority $(M=53.38, \mathrm{SD}=20.26$; Table 7$)$.

Table 5:

Descriptive statistics for high priority tasks.

\begin{tabular}{llllll}
\hline & Mode & Mean & Std. Deviation & Statistic & Std. Error \\
& & & & & .150 \\
\hline $\begin{array}{l}\text { No. of High Priority } \\
\text { Tasks }\end{array}$ & 5 & 4.63 & 1.885 & .247 & \\
\hline Note. $\mathrm{n}=263$ & & & &
\end{tabular}

Table 6:

Frequency table for high priority tasks

\begin{tabular}{|c|c|c|c|c|c|}
\hline & & Frequency & Percent & Valid Percent & Cumulative Percent \\
\hline \multirow{13}{*}{ Valid } & 0 & 3 & 1.1 & 1.1 & 1.1 \\
\hline & 1 & 7 & 2.7 & 2.7 & 3.8 \\
\hline & 2 & 20 & 7.6 & 7.6 & 11.4 \\
\hline & 3 & 44 & 16.7 & 16.7 & 28.1 \\
\hline & 4 & 55 & 20.9 & 20.9 & 49.0 \\
\hline & 5 & 56 & 21.3 & 21.3 & 70.3 \\
\hline & 6 & 33 & 12.5 & 12.5 & 82.9 \\
\hline & 7 & 27 & 10.3 & 10.3 & 93.2 \\
\hline & 8 & 14 & 5.3 & 5.3 & 98.5 \\
\hline & 9 & 1 & .4 & .4 & 98.9 \\
\hline & 10 & 2 & .8 & .8 & 99.6 \\
\hline & 11 & 1 & .4 & .4 & 100.0 \\
\hline & Total & 263 & 100.0 & 100.0 & \\
\hline
\end{tabular}


Table 7:

Descriptive statistics for the percentage of high priority tasks

\begin{tabular}{lll} 
& Mean & Std. Deviation \\
\hline No. of High-Priority Tasks & 53.38 & 20.261 \\
\hline Note. $n=263$
\end{tabular}

Note. $\mathrm{n}=263$

There were also descriptive and frequency statistics calculated to determine how satisfied copy editors were with how their values align with those of the company. The data indicate that on average, respondents were slightly satisfied with how their values aligned with those of the companies $(M=5.93, S D=2.81$; Table 8$)$. However, 40 percent of copy editors were at some level dissatisfied with how their values aligned (Table 9) and gave a rating between 0 (extremely dissatisfied) and 4 (slightly dissatisfied). Therefore, the hypothesis is not supported.

Table 8:

Descriptive statistics for how satisfied copy editors were with how their values align with those of the company

\begin{tabular}{|c|c|c|c|c|c|c|c|}
\hline & \multirow[b]{2}{*}{ Minimum } & \multirow[b]{2}{*}{ Maximum } & \multirow[b]{2}{*}{ Mode } & \multirow[b]{2}{*}{ Mean } & \multirow[b]{2}{*}{$\begin{array}{l}\text { Std. } \\
\text { Deviation }\end{array}$} & \multicolumn{2}{|c|}{ Skewness } \\
\hline & & & & & & Statistic & $\begin{array}{l}\text { Std. } \\
\text { Error }\end{array}$ \\
\hline $\begin{array}{l}\text { Value alignment } \\
\text { Valid } \mathrm{N} \\
\text { (listwise) }\end{array}$ & 0 & 10 & 7 & 5.93 & 2.809 & -.394 & .153 \\
\hline
\end{tabular}


Table 9:

Frequency statistics for satisfaction with value alignment

\begin{tabular}{llrrrr}
\hline & \multicolumn{2}{c}{ Frequency } & Percent & Valid Percent & Cumulative Percent \\
\hline \multirow{6}{*}{} & 0 & 8 & 3.0 & 3.2 & 3.2 \\
& 1 & 16 & 6.1 & 6.3 & 9.5 \\
& 2 & 13 & 4.9 & 5.1 & 14.6 \\
& 3 & 20 & 7.6 & 7.9 & 22.5 \\
& 4 & 15 & 5.7 & 5.9 & 28.5 \\
Valid & 5 & 35 & 13.3 & 13.8 & 42.3 \\
& 6 & 23 & 8.7 & 9.1 & 51.4 \\
& 7 & 36 & 13.7 & 14.2 & 65.6 \\
& 8 & 35 & 13.3 & 13.8 & 79.4 \\
& 9 & 27 & 10.3 & 10.7 & 90.1 \\
& 10 & 25 & 9.5 & 9.9 & 100.0 \\
Missing & Total & 253 & 96.2 & 100.0 & \\
\hline
\end{tabular}

Note: Those that didn't respond were excluded. 
Hypothesis 1: Copy editors' satisfaction of how their values align with those of the company is the best predictor of job satisfaction.

A multiple linear regression was calculated to find how the satisfaction variables (salary, shift hours, co-workers, value alignment, understanding expectations, agreement among expectations, ability to meet expectations, quality of work and variety of expectations) and the controls (job length, industry length, copy editor length, age, education and gender) predicted overall job satisfaction.

There was a significant regression equation found, $(f(16,191)=36.849, p<.001$; Table 14) and $R^{2}=.57$ (Table 11). A significant regression equation was expected because the survey was designed to see how each satisfaction variable contributed to respondents' overall job satisfaction. The controls, job length $(p=.977)$, industry length $(p=.705)$, copy editor length $(p=.659)$, age $(p=.947)$, gender $(p=.759)$ and education $(p=.175)$, were found to be non-significant.

This hypothesis designed to ask about value alignment. Data indicate value alignment was a significant predictor of overall job satisfaction $(p<.001$; Table 13). However, this hypothesis wanted to know whether value alignment was the leading predicting variable. Salary was also a significant variable $(p<.001$; Table 13$)$. Value alignment had a larger Beta value $(\beta=.264)$ than salary $(\beta=.225$; Table 13$)$ and therefore was the best predicting variable and the hypothesis was supported.

A Pearson correlation coefficient was calculated and found that value alignment was the most highly correlated variable with overall job satisfaction $(r(249)=.538, p<$ .001 ; Table 16), while salary had a lower correlation $(r(246)=.410, p<.001$; Table 14$)$. 
Hypothesis 2: Leading predictors of job satisfaction are those indicative of role conflict or role ambiguity apart from value alignment (satisfaction with understanding expectations, satisfaction with agreement of expectations, satisfaction with ability to meet expectations, satisfaction with variety of expectations).

A multiple linear regression was calculated to find how the satisfaction variables (salary, shift hours, co-workers, value alignment, understanding expectations, agreement among expectations, ability to meet expectations and variety of expectations) and the controls (job length, industry length, copy editor length, age, education and gender) predicted overall job satisfaction.

There was a significant regression equation found $(F(16,191)=36.849, p<.001$; Table 12) and $R^{2}=.570$ (Table 11), which was to be expected since the respondents indicated how each contribute to their overall satisfaction. The controls, job length ( $p=$ $.977)$, industry length $(p=.705)$, copy editor length $(p=.659)$, age $(p=.947)$, gender $(p=$ $.759)$ and education $(p=.175)$ were found to be non-significant.

This hypothes is was designed to ask about indicators of role conflict and ambiguity. Data indicate that two variables indicative of role conflict or role ambiguity were significant predictors of overall job satisfaction: satisfaction with quality of work ( $p$ $=.006)$ and value alignment $(p<.001$; Table 13). Other variables were not significant predictors including agreement among job responsibilities $(p=.189)$, understanding job expectations $(p=.169)$, ability to meet expectations $(p=.058)$ and variety of tasks completed ( $p=.373$; Table 13). Therefore, the hypothesis was partially supported. However, collinearity among variables indicative of role conflict and role ambiguity might have impacted the regression. A Pearson correlation coefficient was 
calculated to determine how each variable interacted with overall job satisfaction. Value alignment was significantly moderately correlated $(r(249)=.538, p<.001)$ as was the ability to meet expectations $(r(254)=.448, p<.001)$, quality of work $(r(256)=.505, p<$ $.001)$ and understanding job expectations $(r(250)=.385, p<.001$; Table 12). Therefore, the hypothesis was partially supported.

Table 10

Descriptive statistics for regression predicting overall job satisfaction

\begin{tabular}{lrrr}
\hline & N & Mean & Std. Deviation \\
\hline Job satisfaction & 256 & 6.44 & 2.362 \\
Salary & 250 & 5.25 & 2.770 \\
Shift hours & 254 & 5.99 & 2.761 \\
Co-workers & 262 & 7.75 & 2.217 \\
Quality & 261 & 7.52 & 2.102 \\
Variety & 261 & 6.95 & 2.292 \\
Accuracy for reader & 263 & 7.79 & 1.967 \\
Agreement & 254 & 6.42 & 2.515 \\
Understanding & 255 & 7.33 & 2.319 \\
Ability & 259 & 7.64 & 2.169 \\
Values & 253 & 5.93 & 2.809 \\
Job Length & 249 & 8.82 & 8.963 \\
Industry Length & 255 & 18.76 & 12.651 \\
Copy Editor Length & 252 & 14.56 & 10.525 \\
Age & 250 & 41.95 & 13.456 \\
Education & 258 & 4.10 & .552 \\
Gender & 257 & 1.50 & .501 \\
Valid N (listwise) & 208 & & \\
\hline Vo: Those & & &
\end{tabular}

Note: Those that didn't respond were excluded.

Table 11:

Variance statistics for regression predicting overall job satisfaction

\begin{tabular}{lrrrr}
\hline Model & R & R Square & Adjusted R Square & $\begin{array}{r}\text { Std. Error of the } \\
\text { Estimate }\end{array}$ \\
\hline 1 & $.755^{\mathrm{a}}$ & .570 & .534 & 1.518 \\
\hline
\end{tabular}


Table 12:

Significance values for regression predicting overall job satisfaction ANOVA $^{\text {a }}$

\begin{tabular}{rlrrrrr}
\hline Model & & Sum of Squares & df & Mean Square & F & Sig. \\
\hline \multirow{3}{*}{1} & Regression & 583.820 & 16 & 36.489 & 15.836 & $>.001^{\mathrm{b}}$ \\
& Residual & 440.099 & 191 & 2.304 & & \\
& Total & 1023.918 & 207 & & & \\
\hline
\end{tabular}

Table 13:

Multiple regression predicting overall job satisfaction

\begin{tabular}{|c|c|c|c|}
\hline \multicolumn{4}{|c|}{ Standardized Coefficients } \\
\hline & Beta & $\mathrm{t}$ & Sig. \\
\hline Constant & & .048 & .961 \\
\hline Salary & .225 & 4.206 & $>.001$ \\
\hline Shift hours & .183 & 3.501 & .001 \\
\hline Co-workers & -.029 & -.545 & .587 \\
\hline Quality & .179 & 2.759 & .006 \\
\hline Variety & .056 & .894 & .373 \\
\hline Accuracy for readers & .108 & 1.617 & .107 \\
\hline Agreement & .099 & 1.318 & .189 \\
\hline Understanding & -.097 & -1.379 & .169 \\
\hline Ability & .122 & 1.905 & .058 \\
\hline Value Alignment & .264 & 4.464 & $>.001$ \\
\hline Job Length & -.002 & -.029 & .977 \\
\hline Industry Length & -.052 & -.379 & .705 \\
\hline Copy Editor Length & -.044 & -.442 & .659 \\
\hline Age & -.007 & -.067 & .947 \\
\hline Gender & -.015 & -.308 & .759 \\
\hline Education & .071 & 1.361 & .175 \\
\hline
\end{tabular}


Table 14:

Pearson correlation coefficients for regression predicting overall job satisfaction

\begin{tabular}{|c|c|c|c|c|c|c|c|c|}
\hline & Job Satisfaction & Salary & Shift hours & Co-workers & Quality & Variety & $\begin{array}{r}\text { Accuracy for } \\
\text { readers }\end{array}$ & Agreement \\
\hline Job Satisfaction & 1 & $.410 * *$ & $.345 * *$ & $.250 * *$ & $.505^{* *}$ & $.466^{* *}$ & $.499 * *$ & $.489 * *$ \\
\hline Salary & $.410 * *$ & 1 & $.315 * *$ & $.224 * *$ & $.234 * *$ & $.234 * *$ & $.249 * *$ & $.249 * *$ \\
\hline Shift Hours & $.345 * *$ & $.315^{* *}$ & 1 & $.172 *$ & $.234 * *$ & $.182 * *$ & .122 & $.230 * *$ \\
\hline Co-workers & $.250 * *$ & $.224 * *$ & $.172 * *$ & 1 & .315 & .260 & $.303 * *$ & $.275^{* *}$ \\
\hline Quality & $.505^{* *}$ & $.234 * *$ & $.234 * *$ & $.315^{* *}$ & 1 & $.468 * *$ & $.605^{* *}$ & $.468 * *$ \\
\hline Variety & $.466^{* *}$ & $.234 * *$ & $.182 * *$ & $.260 * *$ & $.468 * *$ & 1 & $.480 * *$ & $.494 * *$ \\
\hline $\begin{array}{l}\text { Accuracy for } \\
\text { readers }\end{array}$ & $.499 * *$ & $.249 * *$ & .122 & $.303 * *$ & $.605 * *$ & $.480 * *$ & 1 & $.446 * *$ \\
\hline Agreement & $.489 * *$ & $.249 * *$ & $.203 * *$ & $.275^{* *}$ & $.468 * *$ & $.494 * *$ & $.446^{* *}$ & 1 \\
\hline Understand & $.385 * *$ & $.218^{* *}$ & $.190 * *$ & $.220 * *$ & $.377 * *$ & $.436 * *$ & $.339 * *$ & $.647 * *$ \\
\hline Ability & $.448 * *$ & $.155^{* *} *$ & .072 & $.142 * *$ & $.459 * *$ & $.410^{* *}$ & $.471 * *$ & $.537 * *$ \\
\hline Values & $.538 * *$ & $.230 * *$ & $.196 * *$ & $.286^{* *} *$ & $.325 * *$ & $.360 * *$ & $.479 * *$ & $.429 * *$ \\
\hline Job Length & -.084 & .085 & -.071 & .043 & -.022 & -.091 & -.062 & -.179 \\
\hline Industry Length & $-.148^{*}$ & -.004 & -.059 & -.043 & -.064 & -.062 & -.016 & $-.160 *$ \\
\hline Copy editor length & -.106 & .055 & .025 & -.031 & -.070 & -.044 & -.045 & $-.149 *$ \\
\hline Age & -.109 & -.005 & -.024 & -.017 & -.031 & -.008 & .009 & -.112 \\
\hline Education & $.155^{*}$ & .105 & .085 & .118 & -.118 & .054 & .111 & -.002 \\
\hline Gender & $.159 *$ & .023 & .096 & $.134 *$ & $.161 *$ & .099 & .032 & .105 \\
\hline
\end{tabular}




\begin{tabular}{|c|c|c|c|c|c|c|c|c|c|}
\hline & $\begin{array}{l}\text { Understand } \\
\text { expectations }\end{array}$ & $\begin{array}{r}\text { Meet } \\
\text { expectations }\end{array}$ & Values & $\begin{array}{r}\text { Job } \\
\text { Length }\end{array}$ & $\begin{array}{r}\text { Industry } \\
\text { Length }\end{array}$ & $\begin{array}{l}\text { Copy } \\
\text { editor } \\
\text { length }\end{array}$ & Age & Education & Gender \\
\hline Job Satis faction & .385 & $.448 * *$ & $.538^{* *}$ & -.084 & $-.148^{*}$ & -.106 & -.109 & $.155^{*}$ & $.159 *$ \\
\hline Salary & $.218^{* *}$ & .155 & $.230 * *$ & .085 & -.004 & .055 & -.005 & .105 & .023 \\
\hline Shift Hours & $.190 * *$ & .072 & .196 & -.071 & -.059 & .025 & -.024 & .085 & .096 \\
\hline Co-workers & $.220 * *$ & $.142 *$ & $.286^{* *}$ & .043 & -.043 & -.031 & -.017 & -.012 & $.134^{*}$ \\
\hline Quality & $.377 * *$ & $.459 * *$ & $.325^{* *}$ & -.022 & -.064 & -.070 & -.031 & -.118 & $.161 * *$ \\
\hline Variety & $.436^{* *}$ & $.410 * *$ & $.360 * *$ & -.091 & -.062 & -.044 & .008 & .054 & .099 \\
\hline $\begin{array}{l}\text { Accuracy for } \\
\text { readers }\end{array}$ & $.339 * *$ & $.471 * *$ & $.479 * *$ & -.062 & -.016 & -.045 & .009 & .111 & .032 \\
\hline Agreement & $.647 * *$ & $.537 * *$ & $.429 * *$ & $-.179 * *$ & $-.160 *$ & $-.149 *$ & -.112 & -.002 & .105 \\
\hline $\begin{array}{l}\text { Understand } \\
\text { expectations }\end{array}$ & 1 & $.500 * *$ & $.323^{* *}$ & -.125 & -.098 & -.162 & -.046 & .037 & .155 \\
\hline $\begin{array}{l}\text { Meet } \\
\text { expectations }\end{array}$ & $.500 * *$ & 1 & $.323^{* *}$ & -.104 & -.110 & -.117 & -.060 . & .021 & $.127^{*}$ \\
\hline Values & $.323^{* *}$ & $.445^{* *}$ & 1 & -.061 & -.038 & -.057 & -.039 & .020 & .077 \\
\hline Job Length & -.125 & -.104 & -.061 & 1 & $.641 * *$ & $.662 * *$ & $.563 * *$ & -.124 & -.114 \\
\hline Industry Length & -.098 & -.110 & -.038 & $.641 * *$ & 1 & $.844 * *$ & $.904 * *$ & -.037 & $-.302 * *$ \\
\hline $\begin{array}{l}\text { Copy editor } \\
\text { length }\end{array}$ & $-.162 *$ & -.117 & -.057 & $.662 * *$ & $.844 * *$ & 1 & $.762 * *$ & .010 & $-.196^{*}$ \\
\hline Age & -.046 & -.060 & -.039 & $.563 * *$ & $.904 * *$ & $.762 * *$ & 1 & -.012 & $-.271 * *$ \\
\hline Education & .037 & .021 & .020 & -.124 & -.037 & .010 & -.012 & 1 & .013 \\
\hline Gender & $.155^{*}$ & .127 & .077 & -.114 & -.302 & $-.196 * *$ & -.271 & .013 & 1 \\
\hline
\end{tabular}


Hypothesis 3: How copy editors prioritize copy editing and the frequency they indicate stories can be published online predict the frequency they do publish stories online prior to editing.

A multiple regression was calculated to see how respondents' opinion of preedited online publication, the priority of traditional copy editing, and the controls (job length, industry length, copy editor length, age, education, and gender) predicted the frequency of publishing online prior to editing. The regression equation was not significant $(F(8,149)=.580), p=.793$; Table 19) and $R^{2}=.030$ (Table 16). The opinion of publishing online $(p=.221)$ and the priority of traditional copy editing $(p=.388$; Table 18) were not significant predictors.

A Pearson correlation coefficient was calculated for how frequently respondents publish prior to editing, the priority of traditional editing, and the opinion of pre-edited online publication. There were no significant relationships between the dependent variable and the independent variables: priority of traditional copy editing $(r(196)=-$ $.094, p=.191)$ and opinion of pre-edit online publication $(r(174)=.133, \mathrm{p}=.080$; Table 17). However, it is key to note that the data indicate a significant weak negative relationship was found between the priority of traditional editing and opinion of preedited publication $(r(213)=-.190$ and $p=.005$. $)$ The controls, job length $(r(189)=.034$, $p=.647)$, industry length $(r(194)=.067, p=.356)$, copy editor length $(r(193)=.040, p$ $=.582)$, age $(r(190)=.079, p=.280)$, education $(r(417)=-.058, p=.417)$ and gender $(r(195)=-.030, p=.680)$ were not significantly correlated with the frequency of preedited publication (Table 19). 
Table 15

Descriptive statistics for regression predicting frequency of pre-edited publication (with opinion and priority of traditional values as independent variables)

\section{Descriptive Statistics}

\begin{tabular}{lccccr}
\hline & N & Minimum & Maximum & Mean & Std. Deviation \\
\hline Opinion of Pre-Edit & 216 & 0 & 10 & 2.87 & 2.901 \\
Publication & & & & & \\
P_Traditional Editing & 260 & 2 & 10 & 9.08 & 1.640 \\
Pre-Edit Publication & 199 & 0 & 10 & 4.14 & 3.393 \\
Valid N (listwise) & 171 & & & & \\
\hline
\end{tabular}

Table 16

Variance statistics for regression predicting frequency of pre-edited publication (with opinion and priority of traditional values as independent variables)

\section{Model Summary}

\begin{tabular}{lrrrr}
\hline Model & $\mathrm{R}$ & R Square & Adjusted R Square & \multicolumn{2}{c}{$\begin{array}{c}\text { Std. Error of the } \\
\text { Estimate }\end{array}$} \\
\hline 1 & $.174^{\mathrm{a}}$ & .030 & -.022 & 3.393 \\
\hline
\end{tabular}

Table 17

Significance values for regression predicting frequency of pre-edited publication (with opinion and priority of traditional values as independent variables)

ANOVA $^{a}$

\begin{tabular}{lrrrrr}
\hline & Sum of Squares & df & Mean Square & F & \multicolumn{1}{c}{ Sig. } \\
\hline Regression & 53.398 & 8 & 6.675 & .580 & $.793^{\mathrm{b}}$ \\
Residual & 1715.646 & 149 & 11.514 & & \\
Total & 1769.044 & 157 & & & \\
\hline
\end{tabular}


Table 18

Multiple regression predicting for frequency of pre-edited publication (with opinion, priority of traditional values as independent variables)

\section{Coefficients $^{\text {a }}$}

\begin{tabular}{|c|c|c|c|}
\hline & \multicolumn{3}{|l|}{ Standardized Coefficients } \\
\hline & Beta & $\mathrm{t}$ & Sig. \\
\hline (Constant) & & 1.859 & .065 \\
\hline Opinion & .103 & 1.228 & .221 \\
\hline P_Traditional Editing & -.075 & -.865 & .388 \\
\hline Job Length & -.039 & -.350 & .727 \\
\hline Industry Length & .069 & .313 & .755 \\
\hline Copy Editor Length & -.026 & -.166 & .869 \\
\hline Age & .076 & .459 & .647 \\
\hline Education & -.044 & -.533 & .595 \\
\hline Gender & -.007 & -.077 & .939 \\
\hline
\end{tabular}

Note. P_Traditional Editing is the traditional editing priority variable. 
Table 19

Pearson correlation coefficients for regression predicting frequency of pre-edited publication (with opinion, priority of traditional values as independent variables)

\section{Correlations}

\begin{tabular}{|c|c|c|c|c|c|c|c|c|c|}
\hline & $\begin{array}{l}\text { Frequency of } \\
\text { pre-edit }\end{array}$ & $\begin{array}{l}\text { Priority of } \\
\text { edits }\end{array}$ & Opinion & Job Length & $\begin{array}{l}\text { Industry } \\
\text { Length }\end{array}$ & $\begin{array}{l}\text { Copy editor } \\
\text { length }\end{array}$ & Age & Education & Gender \\
\hline $\begin{array}{l}\text { Frequency of } \\
\text { pre-edit }\end{array}$ & 1 & -.094 & .133 & .034 & .067 & .040 & .079 & -.058 & -.030 \\
\hline $\begin{array}{l}\text { P_Traditional } \\
\text { Editing }\end{array}$ & -.094 & 1 & $-.190 * *$ & .071 & .068 & $.172 * *$ & .099 & .002 & $.124 *$ \\
\hline Opinion & .133 & $-.190 * *$ & 1 & -.091 & -.105 & $-.173^{*}$ & -.118 & .091 & -.074 \\
\hline Job Length & .034 & .071 & -.091 & 1 & $.641 * *$ & $.662 * *$ & $.563^{* *}$ & -.124 & -.114 \\
\hline Industry Length & .067 & .068 & -.105 & $.641 * *$ & 1 & $.844 * *$ & .904 & -.037 & $-.302 * *$ \\
\hline $\begin{array}{l}\text { Copy editor } \\
\text { length }\end{array}$ & .040 & $.172 * *$ & $-.173 *$ & $.662 * *$ & $.884 * *$ & 1 & $.762 * *$ & .010 & $-.196 * *$ \\
\hline Age & .079 & .099 & -.118 & .563 & .904 & .762 & 1 & -.012 & .271 \\
\hline Education & -.058 & .002 & .091 & -124 & -.037 & .010 & -.012 & 1 & .013 \\
\hline Gender & -.030 & $.124^{*}$ & -.074 & -.114 & $-.302 * *$ & $-.196 * *$ & $-.271 * *$ & .013 & 1 \\
\hline
\end{tabular}

Note. $* \mathrm{p}<.05 . * * \mathrm{p}<.01$ 
Hypothesis 4: The respondents' value of traditional copy editing and respondents' opinion of publishing stories before editing has a negative relationship with how frequently stories are published online before editing.

A multiple linear regression was calculated predicting how frequently copy editors publish stories online based on their value of traditional copy editing, opinion of pre-edited online publication and controls (job length, industry length, copy editor length, age, education, and gender). The regression equation was not significant $(F(8,150)=$ $.554, p=.814$; Table 22) and $R^{2}=.029$ (Table 21). Neither the value of traditional editing $(p=.627)$ or the opinion of publishing prior to editing $(p=.208)$ was significant and therefore the hypothesis was not supported (Table 23).

A Pearson correlation coefficient was calculated to determine if any of the independent variables correlated with the dependent variable. The data indicate that there are no significant correlations. The frequency of pre-edit publication was not correlated with value of traditional editing $(r(197)=-.067, p=.349)$ or opinion of pre-edit publication $(r(174)=.133, p=.080)$. The controls, job length $(r(189)=.034, p=.647)$, industry length $(r(194)=.067, p=.356)$, copy editor length $(r(193)=.040, p=.582)$, age $(r(190)=.079, p=.280)$, education $(r(417)=-.058, p=.417)$ and gender $(r(195)=-.030$, $p=.680$ ) were not significantly correlated with the frequency of pre-edited publication (Table 24). 
Table 20

Descriptive statistics for regression predicting frequency of pre-edited publication (with opinion and value of traditional editing as independent variables)

Descriptive Statistics

\begin{tabular}{|c|c|c|c|c|c|}
\hline & $\mathrm{N}$ & Minimum & Maximum & Mean & Std. Deviation \\
\hline $\begin{array}{l}\text { Opinion of Pre-Edit } \\
\text { Publication }\end{array}$ & 216 & 0 & 10 & 2.87 & 2.901 \\
\hline V_Traditional Editing & 261 & 2 & 10 & 9.20 & 1.648 \\
\hline $\begin{array}{l}\text { Frequency of Pre-Edit } \\
\text { Publication }\end{array}$ & 199 & 0 & 10 & 4.14 & 3.393 \\
\hline Valid N (listwise) & 172 & & & & \\
\hline
\end{tabular}

Table 21

Variance statistics for regression predicting frequency of pre-edited publication (with opinion and value of traditional editing as independent variables)

\section{Model Summary}

\begin{tabular}{|c|c|c|c|c|}
\hline Model & $\mathrm{R}$ & R Square & Adjusted R Square & Std. Error of the Estimate \\
\hline 1 & $.169^{\mathrm{a}}$ & .029 & -.023 & 3.420 \\
\hline
\end{tabular}

Table 22

Significance values for regression predicting frequency of pre-edited publication (with opinion and value of traditional editing as independent variables)

\begin{tabular}{rlrrrrr}
\multicolumn{8}{c}{ ANOVA $^{\mathbf{a}}$} \\
\hline Model & & Sum of Squares & df & Mean Square & F & \multicolumn{1}{c}{ Sig. } \\
\hline \multirow{3}{*}{1} & Regression & 51.857 & 8 & 6.482 & .554 & $.814^{\mathrm{b}}$ \\
& Residual & 1754.873 & 150 & 11.699 & & \\
& Total & 1806.730 & 158 & & & \\
\hline
\end{tabular}


Table 23

Multiple regression predicting frequency of pre-edited publication (with opinion and value of traditional editing as independent variables)

Coefficients $^{\text {a }}$

\begin{tabular}{lcrrr}
\hline & \multicolumn{2}{c}{ Standardized Coefficients } & & \\
\cline { 2 - 3 } & \multicolumn{2}{c}{ Beta } & & \multicolumn{1}{c}{ Sig. } \\
\cline { 2 - 4 } (Constant) & & $\mathrm{t}$ & 1.623 & .107 \\
Opinion & .106 & & 1.266 & .208 \\
V_Traditional Editing & -.041 & -.487 & .627 \\
Job Length & -.051 & -.462 & .645 \\
Industry Length & .114 & .513 & .609 \\
Copy Editor Length & -.032 & -.202 & .840 \\
Age & .059 & .352 & .725 \\
Education & -.051 & -.613 & .541 \\
Gender & .014 & .154 & .878 \\
\hline
\end{tabular}


Table 24

Pearson correlation coefficients for regression predicting frequency of pre-edited publication (with opinion and value of traditional editing as independent variables)

\section{Correlations}

\begin{tabular}{|c|c|c|c|c|c|c|c|c|c|}
\hline & $\begin{array}{l}\text { Frequency of } \\
\text { pre-edit }\end{array}$ & $\begin{array}{l}\text { Value_- } \\
\text { Traditional } \\
\text { editing }\end{array}$ & Opinion & Job Length & $\begin{array}{l}\text { Industry } \\
\text { Length }\end{array}$ & $\begin{array}{l}\text { Copy editor } \\
\text { length }\end{array}$ & Age & Education & Gender \\
\hline $\begin{array}{l}\text { Frequency of } \\
\text { pre-edit }\end{array}$ & 1 & -.067 & .133 & .034 & .067 & .040 & .079 & -.058 & -.030 \\
\hline $\begin{array}{l}\text { V_Traditional } \\
\text { Editing }\end{array}$ & -.067 & 1 & $-.204 * *$ & .107 & .072 & $.153^{*}$ & .092 & -.001 & $.177 * *$ \\
\hline Opinion & .133 & $-.204 * *$ & 1 & -.091 & -.105 & $-.173^{*}$ & -.118 & .091 & -.074 \\
\hline Job Length & .034 & .107 & -.091 & 1 & $.641 * *$ & $.662 * *$ & $.563^{* *}$ & -.124 & -.114 \\
\hline Industry Length & .067 & .072 & -.105 & $.641 * *$ & 1 & $.844 * *$ & $.904 * *$ & -.037 & $-.302 * *$ \\
\hline $\begin{array}{l}\text { Copy editor } \\
\text { length }\end{array}$ & .040 & $.153^{*}$ & $-.173^{*}$ & $.662 * *$ & $.884 * *$ & 1 & $.762 * *$ & .010 & $-.196 * *$ \\
\hline Age & .079 & .092 & -.118 & $.563 * *$ & $.904 * *$ & $.762 * *$ & 1 & -.012 & $.271 * *$ \\
\hline Education & -.058 & -.001 & .091 & -124 & -.037 & .010 & -.012 & 1 & .013 \\
\hline Gender & -.030 & $.177 * *$ & -.074 & -.114 & $-.302 * *$ & $-.196 * *$ & $-.271 * *$ & .013 & 1 \\
\hline
\end{tabular}

Note. The V-Traditional Editing is the value of traditional editing variable.

$* \mathrm{p}<.05 . * * \mathrm{p}<.01$ 
Hypothesis 5: The frequency that copy editors indicate responsibilities conflict for time/attention is positively correlated with the number of tasks copy editors indicate are part of their responsibility and the number of tasks copy editors indicate are high priority.

A multiple linear regression was calculated to predict the respondent's frequency of responsibility conflict based on the number of responsibilities, the number of high priority responsibilities and the controls (job length, industry length, copy editor length, age, education and gender).

A significant regression equation was found $(F(8,214)=6.493, p<.001$; Table 27) and $R^{2}=.195$ (Table 26). The number of responsibilities was a strong predictor ( $\beta=$ $.351, p<.001)$. However, the number of high priority tasks was not a predictor variable $(p=.368 ;$ Table 28).

However, this hypothesis was designed to look at correlations, not predictions. A Pearson correlation coefficient was calculated for the relationship between the respondents' number of responsibilities and frequency of responsibility competition. There was a significant moderate correlation between the number of responsibilities and the frequency of competition. $(r(249)=.333, p<.001$; Table 27$)$. There was a significant weak relationship between the number of high priority and the frequency of responsibility competition $(r(249)=.165, p=.009)$. The controls, job length $(r(235)=-.034, p=.603)$, industry length $(r(241)=.048, p=.458)$, copy editor length $(r(239)=.068, p=.297)$, age $(r(236)=.050, p=.445)$, education $(r(244)=.015, p=.813)$ and gender $(r(243)=-.005$, $p=.936$ ) were not significantly correlated with the frequency of responsibility competition (Table 28).

Therefore the hypothesis was partially supported. 
Table 25

Descriptive statistics for regression of number of tasks predicting responsibility conflict

\begin{tabular}{llllll}
\hline & $\mathrm{N}$ & Minimum & Maximum & Mean & $\begin{array}{l}\text { Std. } \\
\text { Deviation }\end{array}$ \\
\hline Conflict & 249 & 0 & 10 & 4.98 & 2.572 \\
No. of Tasks & 263 & 3 & 13 & 8.84 & 2.298 \\
No. High- & 263 & 0 & 11 & 4.63 & 1.885 \\
$\begin{array}{l}\text { Priority Tasks } \\
\text { Valid N }\end{array}$ & 249 & & & & \\
$($ listwise) & & & & & \\
\hline
\end{tabular}

Table 26

Variance statistics for regression of number of tasks predicting responsibility conflict

\section{Model Summary}

\begin{tabular}{lrrrr}
\hline Model & R & R Square & Adjusted R Square & $\begin{array}{c}\text { Std. Error of the } \\
\text { Estimate }\end{array}$ \\
\hline 1 & $.442^{\mathrm{a}}$ & .195 & .165 & 2.319 \\
\hline
\end{tabular}

Table 27

Significance statistics for regression of number of tasks predicting responsibility conflict ANOVA $^{\mathrm{a}}$

\begin{tabular}{rlrrrrr}
\hline Model & & \multicolumn{1}{c}{$\begin{array}{c}\text { Sum of } \\
\text { Squares }\end{array}$} & df & Mean Square & F & Sig. \\
\hline \multirow{3}{*}{1} & Regression & 279.299 & 8 & 34.912 & 6.493 & $>.001^{\mathrm{b}}$ \\
& Residual & 1150.683 & 214 & 5.377 & & \\
& Total & 1429.982 & 222 & & & \\
\hline
\end{tabular}

a. Dependent Variable: Responsibility Competition 
Table 28

Multiple regression of number of tasks predicting responsibility conflict

Coefficients $^{\mathrm{a}}$

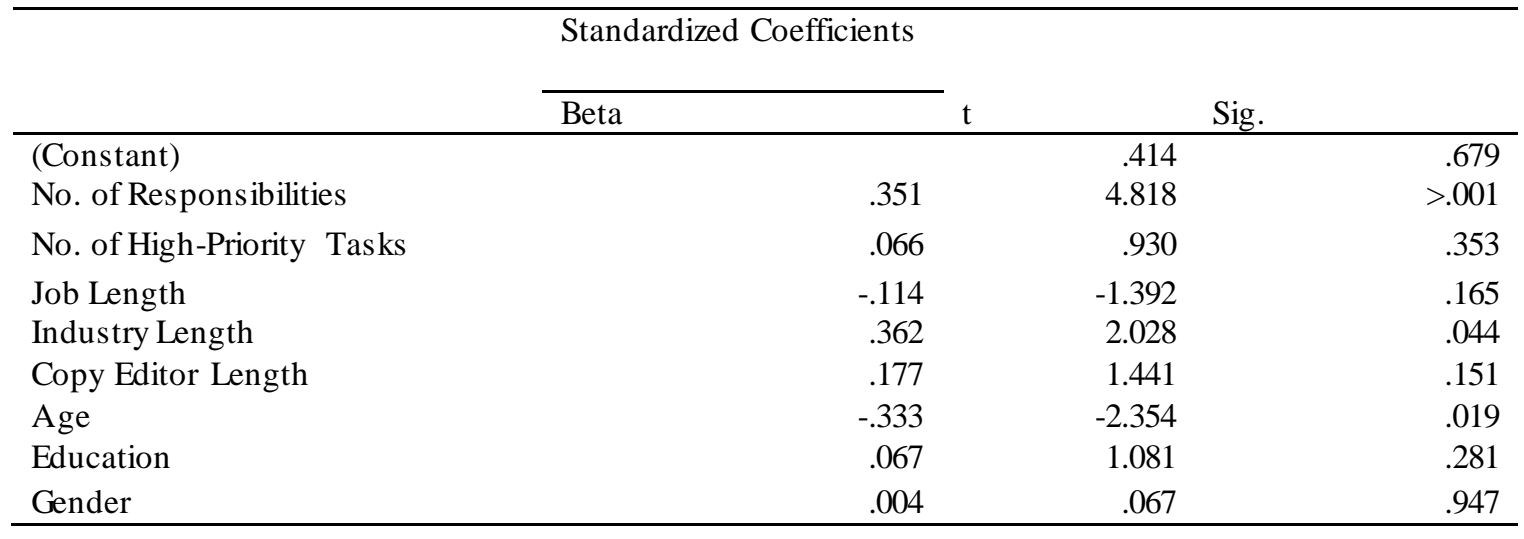


Table 29

Pearson correlation coefficients for regression of number of tasks predicting responsibility conflict

\section{Correlations}

\begin{tabular}{|c|c|c|c|c|c|c|c|c|c|}
\hline & $\begin{array}{l}\text { Responsibility } \\
\text { conflict }\end{array}$ & $\begin{array}{l}\text { Number of } \\
\text { responsibilities }\end{array}$ & $\begin{array}{l}\text { High } \\
\text { priority } \\
\text { tasks }\end{array}$ & $\begin{array}{l}\text { Job } \\
\text { length }\end{array}$ & $\begin{array}{l}\text { Industry } \\
\text { length }\end{array}$ & $\begin{array}{l}\text { Copy } \\
\text { editor } \\
\text { length } \\
\end{array}$ & Age & Education & Gender \\
\hline Conflict & 1 & $.333 * *$ & $.165 * *$ & -.034 & .048 & .068 & -.050 & .015 & -.005 \\
\hline No. of Tasks & $.333 * *$ & 1 & $.469 * *$ & $-.155^{*}$ & $-.185 * *$ & $.186^{* *}$ & $-.224 * *$ & -.029 & -.072 \\
\hline No. of High & $.165^{* *}$ & $.469 * *$ & 1 & -.069 & -.079 & -.066 & -.091 & -.034 & .122 \\
\hline \multicolumn{10}{|l|}{ Priority Tasks } \\
\hline Job length & -.034 & $-.155^{*}$ & -.069 & 1 & $.641 * *$ & $.662 * *$ & $.563^{* *}$ & -.124 & -.144 \\
\hline Industry length & .048 & $-.185 * *$ & -.079 & $.641 * *$ & 1 & $.844 * *$ & $.904 * *$ & -.37 & .302 \\
\hline Copy editor length & .068 & $-.186^{* *}$ & -.066 & $.662 * *$ & $.844 * *$ & 1 & $.762 * *$ & .010 & $.196 * *$ \\
\hline Age & -.050 & $-.224 * *$ & -.091 & $.563 * *$ & $.904 * *$ & $.762 * *$ & 1 & -.012 & .271 \\
\hline Education & .015 & -.029 & -034 & -.124 & -.037 & .010 & -.012 & 1 & .013 \\
\hline Gender & -.005 & -.082 & .122 & -.114 & $-.302 * *$ & $-.196 * *$ & $.271 * *$ & .013 & 1 \\
\hline
\end{tabular}


Hypothesis 6: There is a correlation between the frequency copy editors indicate responsibilities conflict and the types of tasks copy editors indicate make up large portions of their responsibilities. (A hypothesis pertaining to which tasks will impact frequency of conflict was not formed because of a lack of previous research).

A multiple linear regression was calculated to predict the frequency of responsibility competition based on the tasks (aggregation, app updating, local editing, wire editing, layout and design, online photo editing, page proofs, pulling wire, traditional copy editing, website management, social media, writing print headlines, and writing online headlines) and the controls (job length, industry length, copy editor length, age, education, and gender).

A significant regression equation was not found $(f(19,26)=1.832, p=.075$; Table 34) and $R^{2}=.572$ (Table 31). None of them were significant predictors in the equation, the closest were online headlines $(p=.090)$ and social media $(p=.095$; Table 33).

However, this hypothesis wanted to look at the correlation because of the collinearity effect on regression. A Pearson correlation coefficient was calculated to determine the relationship between the frequency of responsibility competition and each responsibility and controls. The Pearson correlation data in Table 36 indicate that social media has a significant moderate correlation with the frequency of responsibility competition $(r(133)=.318, p<.001)$. Website management $(r(166)=.172, p=.027)$ and page proof editing $(r(235)=.145, p=.026)$ had a significant weak relationship with the frequency of responsibility competition. Therefore, social media, website management, and page proof edits are correlated with the frequency of responsibility competition. The controls, job length $(r(235)=-.034, p=.603)$, industry length $(r(241)=.048, p=.458)$, 
copy editor length $(r(239)=.068, p=.297)$, age $(r(236)=.050, p=.445)$, education $(r(244)=.015, p=.813)$ and gender $(r(243)=-.005, p=.936)$ were not significantly correlated with the frequency of responsibility competition.

Therefore the hypothesis was supported.

Table 30

Descriptive statistics for regression of types of tasks predicting responsibility conflict Descriptive Statistics

\begin{tabular}{lrrrrr}
\hline & N & Minimum & Maximum & Mean & Std. Deviation \\
\hline Responsibility Conflict & 249 & 0 & 10 & 4.98 & 2.572 \\
T_Aggregation & 101 & 0 & 10 & 2.00 & 2.494 \\
T_App & 77 & 0 & 9 & .94 & 1.976 \\
T_Local Edits & 248 & 0 & 10 & 8.20 & 2.337 \\
T_Wire Edits & 239 & 0 & 10 & 6.28 & 2.935 \\
T_Layout and Design & 203 & 0 & 10 & 6.62 & 3.708 \\
T_Online Photos & 197 & 0 & 10 & 4.12 & 3.080 \\
T_Proofs & 249 & 0 & 10 & 6.84 & 3.073 \\
T_Pull Wire & 210 & 0 & 10 & 5.62 & 3.400 \\
T_Traditional Editing & 261 & 1 & 10 & 8.61 & 2.030 \\
T_Website Management & 171 & 0 & 10 & 4.49 & 3.024 \\
T_Social Media & 137 & 0 & 10 & 2.97 & 2.958 \\
T_Print Headlines & 253 & 0 & 10 & 7.76 & 2.626 \\
T_Online Headlines & 217 & 0 & 10 & 5.29 & 3.361 \\
Valid N (listwise) & 50 & & & & \\
\hline
\end{tabular}

Note: The "T_" at the beginning of the name indicates it is a responsibility variable.

Table 31

Variance statistics for regression of types of tasks predicting responsibility conflict

\section{Model Summary}

\begin{tabular}{lrrrr}
\hline Model & $\mathrm{R}$ & R Square & Adjusted R Square & \multicolumn{2}{c}{$\begin{array}{c}\text { Std. Error of the } \\
\text { Estimate }\end{array}$} \\
\hline 1 & $.757^{\mathrm{a}}$ & .572 & .260 & 2.433 \\
\hline
\end{tabular}


Table 32

Significance statistics for regression of types of tasks predicting responsibility conflict

\section{ANOVA $^{\mathrm{a}}$}

\begin{tabular}{rlrrrrr}
\hline Model & & Sum of Squares & df & Mean Square & F & \multicolumn{1}{l}{ Sig. } \\
\hline \multirow{3}{*}{1} & Regression & 206.033 & 19 & 10.844 & 1.832 & $.075^{\mathrm{b}}$ \\
& Residual & 153.880 & 26 & 5.918 & & \\
& Total & 359.913 & 45 & & & \\
\hline
\end{tabular}

Table 33

Multiple regression of types of tasks predicting responsibility conflict

\section{Coefficients $^{\mathrm{a}}$}

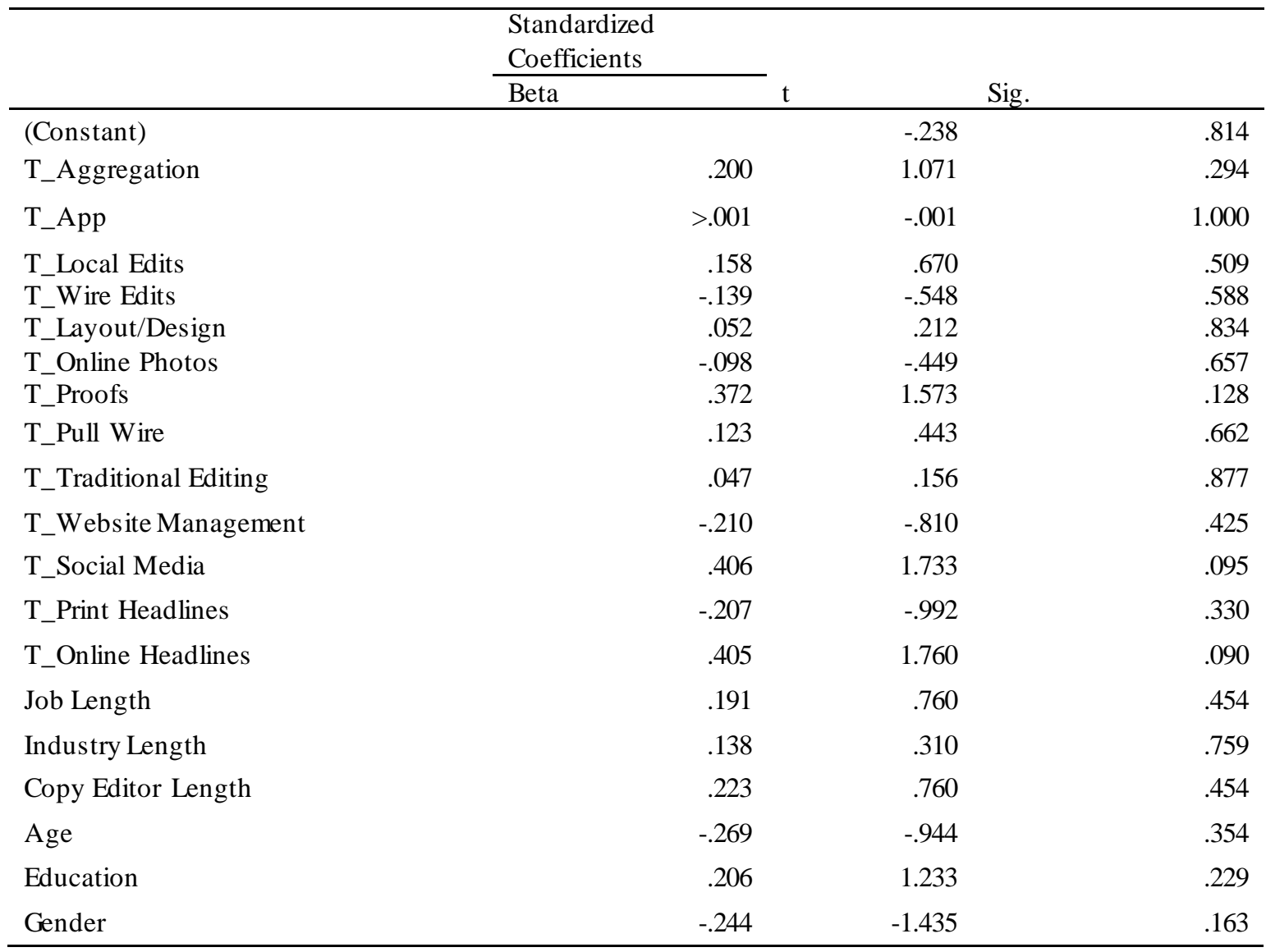

Note: The "T_" at the beginning of the name indicates it is a responsibility variable. 
Table 34

Pearson correlation coefficients for regression of types of tasks predicting responsibility conflict

\section{Correlations}

\begin{tabular}{|c|c|c|c|c|c|c|c|c|}
\hline & Conflict & T_Aggregation & T_App & $\begin{array}{l}\text { T_Local } \\
\text { Edits }\end{array}$ & $\begin{array}{l}\text { T_Wire } \\
\text { Edits }\end{array}$ & $\begin{array}{l}\text { T_Layout, } \\
\text { Design }\end{array}$ & $\begin{array}{l}\text { T_Online } \\
\text { photo }\end{array}$ & T_Proofs \\
\hline Conflict & 1 & .165 & .203 & .104 & .092 & .066 & .112 & .145 \\
\hline T_Aggregation & .165 & 1 & $.465 * *$ & .062 & .045 & .273 & .334 & .033 \\
\hline T_App & .203 & $.465 * *$ & 1 & .061 & -.058 & .133 & .172 & .049 \\
\hline T_Local Edits & .104 & .062 & .061 & 1 & $.484 * *$ & .199 & .122 & $.421 * *$ \\
\hline T_Wire Edits & .092 & 045 & $.028 *$ & .484 & 1 & .331 & .183 & $.535^{* *}$ \\
\hline T_Layout, design & .066 & $.273 *$ & .133 & $.199 * *$ & $.331 * *$ & 1 & .148 & $.401 * *$ \\
\hline T_Online photos & .112 & $.334 * *$ & .174 & .122 & $.183^{*}$ & .148 & 1 & $.221 * *$ \\
\hline T_Proofs & $.145^{*}$ & .033 & .049 & $.421 * *$ & $.535 * *$ & $.401 * *$ & $.221 * *$ & 1 \\
\hline T_Pull wire & .092 & $.224 *$ & .118 & $.381 * *$ & $.621 * *$ & $.646 * *$ & $.228 * *$ & $.526 * *$ \\
\hline $\begin{array}{l}\mathrm{T}_{-} \text {Traditional } \\
\text { editing }\end{array}$ & .016 & .024 & -.008 & $.582 * *$ & $.397 * *$ & .053 & .228 & .482 \\
\hline $\begin{array}{l}\mathrm{T}_{-} \mathrm{Website} \\
\text { management }\end{array}$ & .172 & .332 & .264 & .068 & .088 & .200 & .489 & .072 \\
\hline T_Social media & .318 & .243 & .318 & .084 & .168 & .055 & .293 & .002 \\
\hline T_Print headlines & .071 & .037 & .042 & $.501 * *$ & $.423 * *$ & $.158^{*}$ & $.195 * *$ & $.520 * *$ \\
\hline T_Online headlines & .130 & .280 & .077 & .237 & .279 & .082 & .552 & .217 \\
\hline Job Length & -.034 & $-.200 *$ & -.097 & .046 & -.140 & $-.188^{*}$ & -.026 & -.031 \\
\hline Industry length & .048 & -.088 & -.108 & -.085 & $-.204 * *$ & $-.280 * *$ & -.028 & $-.150 *$ \\
\hline Copy editor length & .068 & -.197 & -.069 & -.022 & $-.227 * *$ & $-.272 * *$ & -.044 & -.095 \\
\hline Age & -.050 & -.162 & -.101 & -.075 & $-.164 * *$ & $-.316^{* *}$ & -.034 & -.124 \\
\hline Education & .015 & -.052 & -.019 & -.113 & -.041 & -.022 & .035 & -.089 \\
\hline Gender & -.005 & .040 & -.040 & .090 & $.166^{*}$ & .038 & .073 & $.188^{* * *}$ \\
\hline
\end{tabular}

Note: The "T " at the beginning of the name indicates it is a responsibility variable.

Table continues on the next page.

$* \mathrm{p}<.05 . * * \mathrm{p}<.01$ 


\begin{tabular}{|c|c|c|c|c|c|c|c|c|}
\hline & T_Pull wire & $\begin{array}{r}\mathrm{T}_{-} \text {Traditional } \\
\text { editing }\end{array}$ & $\begin{array}{r}T_{-} \text {Website } \\
\text { management }\end{array}$ & $\begin{array}{r}\text { T_Social } \\
\text { media }\end{array}$ & $\begin{array}{r}\text { T_Print } \\
\text { headlines }\end{array}$ & $\begin{array}{l}\text { T_Online } \\
\text { headlines }\end{array}$ & Job length & $\begin{array}{r}\text { Industry } \\
\text { length }\end{array}$ \\
\hline Conflict & .092 & -.016 & $.172 *$ & $.318^{* *}$ & .071 & .130 & -.034 & .048 \\
\hline T_Aggregation & $.224 *$ & .024 & $.322 *$ & .243 & .037 & $.280 * *$ & $-.200 *$ & -.088 \\
\hline T_App & .118 & .008 & $.264^{*}$ & $.318^{* *}$ & .042 & .077 & -.097 & -.108 \\
\hline T_Local Edits & $.381 * *$ & $.582 * *$ & .068 & .084 & $.501 * *$ & $.237 *$ & .046 & -.085 \\
\hline T_Wire Edits & $.621 * *$ & $.397 * *$ & .088 & .168 & $.423 * *$ & $.279 * *$ & -.140 & $-.204 * *$ \\
\hline T_Layout, design & $.228 * *$ & .053 & $.200^{*}$ & .055 & $.158^{*}$ & .082 & $-.188 * *$ & $.270 * *$ \\
\hline T_Online photos & $.228 * *$ & $.228 *$ & $.489 * *$ & $.293 * *$ & $.195^{* *}$ & $.552 * *$ & -.026 & $.228 * *$ \\
\hline T_Proofs & $.526^{* *}$ & $.482 * *$ & .072 & .002 & $.520 * *$ & $.217 * *$ & -.031 & $-.150 *$ \\
\hline T_Pull wire & 1 & $.237 * *$ & $.244 * *$ & .135 & $.322 * *$ & $.168^{*}$ & $-.185^{* *}$ & $-.223^{* *}$ \\
\hline T_Traditional editing & $.237 * *$ & 1 & .029 & .034 & $.576^{* *}$ & $.316^{* *}$ & -.007 & -.134 \\
\hline T_Website management & $.244 * *$ & .029 & 1 & $.563 * *$ & .046 & $.575^{* *}$ & $-.201 *$ & $-.186^{*}$ \\
\hline T_Social media & .135 & .034 & $.563 * *$ & 1 & .035 & $.446^{* *}$ & -.105 & -.066 \\
\hline T_Print headlines & $.322 * * *$ & $.576^{* *}$ & .046 & .035 & 1 & $.359 * *$ & .027 & -038 \\
\hline $\mathrm{T} \_$Online headlines & $.168 *$ & $.316^{* *}$ & $.575^{* *}$ & $.446 * *$ & $.359 * *$ & 1 & -.129 & $-.161 *$ \\
\hline Job Length & $-.185^{* *}$ & -.007 & $-.201 * *$ & -.105 & .027 & -.129 & 1 & $.641 * *$ \\
\hline Industry length & $-.223 * *$ & $-.134 *$ & $-.189 *$ & -.066 & -.038 & $-.161 *$ & $.641 * *$ & 1 \\
\hline Copy editor length & $-.231 * *$ & -.037 & $-.220 * *$ & -.018 & .003 & $-.152 *$ & $.662 * *$ & $.844 * *$ \\
\hline Age & $-.246^{* *}$ & -.069 & $-.284 * *$ & -.148 & -.053 & $-.204 * *$ & $.563 * *$ & $.904 * *$ \\
\hline Education & -.089 & -.035 & .078 & .153 & -.015 & .038 & -.124 & -.037 \\
\hline Gender & -.022 & $.197 * *$ & -.031 & -.065 & .081 & $.177^{*}$ & -.114 & $-.302 * *$ \\
\hline
\end{tabular}

Note: The "T_" at the beginning of the name indicates it is a responsibility variable.

Table continues on the next page.

$* \mathrm{p}<.05 . * * \mathrm{p}<.01$ 


\begin{tabular}{|c|c|c|c|c|}
\hline & Copy editor length & Age & Education & Gender \\
\hline Conflict & .068 & -.050 & .015 & -.005 \\
\hline T_Aggregation & -.167 & -.162 & -.052 & .040 \\
\hline T_App & -.069 & -.101 & -.019 & -.040 \\
\hline T_Local Edits & -.022 & -.075 & -.113 & .090 \\
\hline T_Wire Edits & $-.227 * *$ & $-.164 *$ & -.041 & $.166^{*}$ \\
\hline T_Layout, design & $-.272 * *$ & $-.316^{* *}$ & . 022 & .038 \\
\hline T_Online photos & -.044 & -.034 & .035 & .073 \\
\hline T_Proofs & -.095 & -.124 & -.089 & $.188^{* *}$ \\
\hline T_Pull wire & $-.231 * *$ & $-.246 * *$ & -.089 & -.022 \\
\hline $\mathrm{T}$ _Traditional editing & -.037 & -.069 & -.035 & $.197 * *$ \\
\hline $\mathrm{T}_{-}$Website management & $-.220 * *$ & $-.284 * *$ & .078 & -.031 \\
\hline T_Social media & -.018 & -.148 & .153 & -.065 \\
\hline T_Print headlines & .003 & -.053 & -.015 & .081 \\
\hline T_Online headlines & $-.152^{*}$ & $-.204^{*}$ & .038 & $.177^{*}$ \\
\hline Job Length & $.662 * *$ & $.563^{* *}$ & -.124 & $-.114 * *$ \\
\hline Industry length & $-.844 * *$ & $.904 * *$ & -.037 & $-.302 * *$ \\
\hline Copy editor length & 1 & 1 & .010 & $-.196 * *$ \\
\hline Age & $.762 * *$ & -.012 & -.012 & $-.271 * *$ \\
\hline Education & .010 & -.012 & 1 & 013 \\
\hline Gender & $-.196 * *$ & $-.271 * *$ & 013 & 1 \\
\hline
\end{tabular}

Note: The "T_" at the beginning of the name indicates it is a responsibility variable.

$* \mathrm{p}<.05 . * * \mathrm{p}<.01$ 
Hypothesis 7: The frequency of responsibility conflict, the number of tasks, and the frequency of enough time to complete tasks predict the frequency of errors.

A multiple linear regression was calculated to see if the frequency of responsibility conflict, frequency of enough time to complete tasks, the number of tasks, and the controls (job length, industry length, copy editor length, age, education, and gender) predicted the frequency of errors.

A significant regression equation was found $(f(9,210)=7.621, p<.001)$ and $R^{2}=$ .246. None of the controls, job length $(p=.273)$, industry length $(p=.549)$, copy editor length $(p=.880)$, age $(p=.324)$, education $(p=.902)$ and gender $(p=.990)$ were predictor variables. In fact, the number of responsibilities $(p=.102)$ and the frequency of responsibility conflict $(p=.191)$ were not predictor variables. However, having enough time (or not enough) was a strong negative predictor variable $(\beta=-.379, p<.001)$. Therefore the hypothesis is partially supported.

A Pearson correlation coefficient was calculated to how each independent variable correlated with the dependent variable. The data in Table 41 indicate that there is a significant moderate negative correlation between the having enough time to complete tasks and the frequency of errors $(r(256)=-.478, p<.001)$. Therefore, the less time people indicate they have to complete tasks to their personal standards, the more frequently they feel they miss errors. There was also a significant moderate relationship between responsibility competition and the frequency of errors $(r(246)=.309, p<.001)$. There was also a significant weak relationship between the number of responsibilities and the frequency of errors $(r(259)=.201, p=.001)$. The controls, job length $(r(246)=.053$, $p=.410)$, industry length $(r(251)=.066, p=.299)$, copy editor length $(r(248)=.034, p$ 
$=.592)$, age $(r(246)=.011, p=.867)$, education $(r(254)=-.017, p=.784)$, and gender $(r(253)=-.025, p=.698)$ were not significantly correlated with the frequency of responsibility competition.

The hypothesis was supported.

Table 35

Descriptive statistics for regression predicting frequency of errors

\section{Descriptive Statistics}

\begin{tabular}{llrrrr}
\hline & N & Minimum & Maximum & Mean & Std. Deviation \\
\hline Responsibility Conflict & 249 & 0 & 10 & 4.98 & 2.572 \\
Number of Responsibilities & 263 & 3 & 13 & 8.84 & 2.298 \\
Time to Complete Tasks & 259 & 0 & 10 & 5.64 & 2.539 \\
Frequency of errors & 259 & 0 & 10 & 4.78 & 2.398 \\
Valid N (listwise) & 243 & & & & \\
\hline
\end{tabular}

Table 36

Variance statistics for regression predicting frequency of errors

\section{Model Summary}

\begin{tabular}{lrrrr}
\hline Model & $\mathrm{R}$ & R Square & Adjusted R Square & \multicolumn{2}{c}{$\begin{array}{c}\text { Std. Error of the } \\
\text { Estimate }\end{array}$} \\
\hline 1 & $.496^{\mathrm{a}}$ & .246 & .214 & 2.081 \\
\hline
\end{tabular}


Table 37

Significance statistics for regression predicting frequency of errors

ANOVA $^{\mathrm{a}}$

\begin{tabular}{rlrrrrr}
\hline Model & & Sum of Squares & df & Mean Square & F & \multicolumn{1}{c}{ Sig. } \\
\hline \multirow{4}{*}{1} & Regression & 297.088 & 9 & 33.010 & 7.621 & $>.001^{\mathrm{b}}$ \\
& Residual & 909.543 & 210 & 4.331 & & \\
& Total & 1206.632 & 219 & & & \\
\hline
\end{tabular}

Table 38

Multiple regression predicting frequency of errors

\begin{tabular}{llrrr}
\hline & \multicolumn{2}{l}{$\begin{array}{l}\text { Standardized } \\
\text { Coefficients }\end{array}$} & & \\
\cline { 2 - 3 } Beta & & & Sig. \\
\hline Constant) & & 3.669 & $>.001$ \\
No. of Tasks & .112 & 1.645 & .102 \\
Conflict & .095 & 1.313 & .191 \\
Time to Complete Tasks & -.379 & -5.570 & $>.001$ \\
Job Length & .089 & 1.099 & .273 \\
Industry Length & .105 & .600 & .549 \\
Copy Editor Length & -.018 & -.151 & .880 \\
Age & -.138 & -.990 & .324 \\
Education & -.008 & -.123 & .902 \\
Gender & .001 & .013 & .990 \\
\hline
\end{tabular}


Table 39

Pearson correlation coefficient statistics for regression predicting frequency of errors

\begin{tabular}{|c|c|c|c|c|c|c|c|c|c|c|}
\hline & Errors & Time & Conflict & $\begin{array}{l}\text { No. of } \\
\text { tasks }\end{array}$ & $\begin{array}{l}\text { Job } \\
\text { length }\end{array}$ & $\begin{array}{l}\text { Industry } \\
\text { length }\end{array}$ & $\begin{array}{l}\text { Copy } \\
\text { editor } \\
\text { length } \\
\end{array}$ & Age & Education & Gender \\
\hline Errors & - & $-.478 * *$ & $.309 * *$ & $.201 * *$ & -.053 & .066 & .034 & .011 & -.017 & -.025 \\
\hline Time & -.478 & - & $-.464 * *$ & $-.210 * *$ & -.59 & -.109 & -.115 & -.056 & .050 & .057 \\
\hline Conflict & $.309 * *$ & $-.464 * *$ & - & $.333 * *$ & .034 & .048 & .068 & -.050 & .015 & -.005 \\
\hline No. of tasks & $.201 * *$ & $-.210 * *$ & $.333 * *$ & - & $-.155^{* *}$ & $-.185^{* *}$ & $-.186 * *$ & $-.244 * *$ & -.029 & -.072 \\
\hline Job Length & .053 & -.059 & -.034 & $-.155^{* *}$ & - & $.641 * *$ & $.662 * *$ & $.563^{* *}$ & -.124 & -.114 \\
\hline $\begin{array}{l}\text { Industry } \\
\text { length }\end{array}$ & .066 & -.109 & .048 & $-.185^{* *}$ & $.641 * *$ & - & $.844 * *$ & $.904 * *$ & -.037 & $-.302 * *$ \\
\hline $\begin{array}{l}\text { Copy } \\
\text { Editor } \\
\text { Length }\end{array}$ & .034 & -.115 & .068 & -.186 & $.662 * *$ & $.844 * *$ & 1 & $-.762 * *$ & .010 & $-.196 * *$ \\
\hline Age & .011 & -.056 & -.050 & -.224 & $.563 * *$ & $.904 * *$ & $.762 * *$ & - & -.012 & $-.271 * *$ \\
\hline Education & -.017 & .050 & .015 & -.029 & -.124 & .037 & .010 & -.012 & - & .013 \\
\hline Gender & -.025 & .057 & -.005 & -.072 & -.114 & $-.302 * *$ & $-.196 * *$ & $-.271 * *$ & .013 & - \\
\hline
\end{tabular}

$* \mathrm{p}<.05 . * * \mathrm{p}<.01$ 


\section{Discussion}

This study sought to determine if there was evidence of role conflict in copy editors and if that had an impact on their satisfaction and work. The data indicated that there was evidence of role conflict and that social media was most highly correlated with social media. It also found that value alignment was the best predictor variable of overall job satisfaction.

It might be of merit to first delve into the demographics of the respondents in order to have a fuller understanding of the analysis. The average age for a copy editor in this survey was 42 years old, and there was an almost even split among men and women, the data indicate. The average time respondents had been a copy editor was 15 years, and the average time they had been in the media industry was 19 years. This indicates that most copy editors had started out in some other type of position, possibly as a reporter, before moving to the copy desk.

However, not everyone who responded was strictly a copy editor. Many indicated they were a copy editor/designer, which has been seen for a couple decades now and is evidence of role conflict. Others were preparing to make the shift to a dual role — one indicated she was becoming a copy editor and reporter soon. The responses from others, however, indicate how dynamics are changing at the copy desk. It appears the desk is impacted by the digital era because several respondents indicated they were a multiplatform editor or a digital content editor. Similar responses ranged from a web editor to "geo-curator (copy editor)" to deputy managing editor of digital operations. There was also a shift toward centralization. One respondent indicated they were a liaison 
between the newsroom and the copy desk hub. While not in the data set, many managing editors said when they were asked to send the survey on to their copy editors that their editing and/or design was taken care of at a central hub.

However, while the copy editor population is in the midst of shrinking - or at least transforming - others in the newsroom are lending a hand to assist in the copy editing process and view themselves, in some capacity, as copy editors. For example, several respondents indicated they were managing editors, assistant managing editors or simply 'Editors' who spend substantial time editing and designing pages, among other copy editing duties. This might demonstrate the challenges facing the copy desk, or even newspapers in general, which have forced the role conflict that copy editors experience to spread to others in the newsroom who merge copy editing into their other duties.

In addition, many were operating as a copy editor under another title. One wrote she was a paginator who does "everything copy editors do but for less money." But there also seemed to be a sense of role ambiguity and role conflict when another respondent wrote, "Who knows anymore" and another wrote, "I don't have one" about their job titles. There seems to indicate a lack of direction, or at least a lack of cohesion, within the the job title or lack thereof.

With this in mind, the focus can turn toward more quantitative means of examining the evidence and causality of role conflict. On a scale of 0 (never) to 10 (all the time), more than half ranked their frequency of responsibility conflict a 5. $(M=4.98)$. It becomes immediately apparent that research brushes against the limitation that Biddle (1986) discusses: a limited basis of comparison. This research does not compare against other positions, even against those in the newsroom or copy editors who work in different 
industries. It also does not measure the intensity of the role conflict. However, it does indicate that role conflict manifesting itself as responsibility conflict is prevalent, even if it is not overwhelming.

The conflict isn't particularly surprising considering the average number of responsibilities copy editors were expected to complete was 9 out of the 13 tasks $(M=$ 8.86). Briefly, though this will be addressed further in the limitations section, there were only so many responsibilities a quantitative survey could ask about. And therefore, the mean 9 is at a minimum, and there could be additional responsibilities that were not asked about. It also didn't take into consideration the small tasks such as creating a print budget, writing briefs, emails, meetings, etc. The data also indicate that many of these responsibilities are urgent. The respondents indicated that more than half of their responsibilities were highly prioritized $(M=53.38)$.

The number of responsibilities was a key predicting variable in the frequency of responsibility conflict, which means the more responsibilities a person has the more likely they are to experience conflict. How far this stretches cannot be ascertained because the maximum number of choices was 13 , and respondents could have additional tasks. The number of high-priority tasks was not a predicting variable, but that might have been a result of collinearity because it was correlated with role conflict. The number of highly prioritized tasks was not as strongly correlated as the number of tasks with responsibility conflict, but it was still significant.

It might be of merit to note that the Pearson correlation matrix indicated the copy editor length and job length were negatively correlated with the number of tasks. Therefore, younger editors might have more tasks. So, one might expect these controls to 
have a negative correlation with responsibility conflict as well. However, those control factors were not correlated with the responsibility conflict, which might be a result of survey design, miscommunication, or other common data gathering problems. The reason for the lack of correlation is not known.

What the research did find, however, was that certain responsibilities are correlated with how frequently copy editors say they experience conflict as a result of time constraints and responsibility conflict. For instance, copy editors who do more with social media are more likely to indicate they experience role conflict. Perhaps this is because social media is constant and is rarely something a copy editor can set aside 30 minutes of a shift and get entirely done. It keeps coming back as news breaks and might be distracting. Although not as highly correlated, Web management might operate under the same paradigm, where it is broken into a dozens of little tasks that need to be repeated or done again and again throughout the shift. Also indicative of responsibility conflict was looking at page proofs. Again, a firm conclusion about why that is cannot be ascertained from the data, but one possibility might be because proofs come at the end of the night, when people are working on deadline. They might be trying to finish up one of their nine tasks and might associate the page proof with the chaos at the end of the night. In addition, the data indicate almost 30 percent of respondents feel they frequently do not have enough time to complete copy editing in a way that meets their personal standards. This isn't managing editors saying their copy editors aren't doing well; this is copy editors who know that they can be doing their jobs better but are unable to because of time constraints and other responsibilities. It seems that they are conflicted between doing their jobs to the best of their ability and taking care of all the tasks required of 
them. When copy editors feel that they don't have time, they indicate that they miss errors because of the number of responsibilities and time constraints. Therefore, it might be beneficial to consider having copy editors work longer hours on fewer days. For instance, work four 10-hour days rather than five eight-hour days. This especially makes more sense as the media industry enters into a digital-first era, where stories are published online first. It might allow more stories, especially at smaller paper without a dedicated Web team, to be handled earlier in the day by copy editors, which would allow readers to get content faster and ease the backlog that often occurs at the end of the night. It also might give them an extra night to be home for dinner with their families, which might improve copy editors' satisfaction with their shift hours, which is discussed next.

Role conflict also appears to have an emotional connection with respondents who cope with it. Despite the changing copy editing landscape and pressure, copy editors seemed to be happy with their jobs overall $(M=6.4)$. But, the survey drilled down and asked them to say if they were satisfied or dissatisfied with 10 variables. They were the least satisfied with salary $(M=5.25)$ and shift hours $(M=5.99)$, which reiterates what other surveys have said. Those variables were also significant predictors in overall job satisfaction, which was to be expected since each component was intended to be a contributing variable. Rather, it became important to look at the correlations. Value alignment, which has not really been addressed in previous editing research, was found to be a leading indicator of role conflict by Rizzo, et. al (1970). In this study, it was not only a predictor variable but it had the strongest correlation with overall job satisfaction. The discrepancy in value alignment comes when a company expects a copy editor to have 
certain values. These values might not be what the employee values as an independent copy editor, apart from the company.

In addition to value alignment, other indicators of role conflict or role ambiguity were also more strongly correlated than the three other variables and the six controls. It seems that the emotional toll, or benefit, of the job had a larger correlation with job satisfaction than the more concrete aspects such as salary or shift hours. This might happen for a variety of reasons. First, most copy editors generally understand that they won't be making top dollar, it is the news industry after all, and they would probably work nights. But maybe they also thought they were hired to edit copy and help improve the quality of the publication. While the editing might become less valued by the publication, it is unlikely to change for the editor and that might have led to dissatisfaction with how the values align. Although it was not a focus of the research, it is possible that the digital age caused a shift in values in the company, or a perceived shift of values from the view of copy editors. One way the research sought how copy editor values are factored into role conflict was through examining the impact of the digital age.

There was no correlation or significant regression equation among the value of copy editing, the priority of copy editing, the opinion of pre-edited publication, and the frequency of pre-edited publication. There could be many reasons for this, many of which are the normal problems that come with surveys - flaws in the design and/or respondents didn't understand the question. However, there is the possibility copy editors' values and priorities have no bearing on how frequently they publish stories online prior to editing, even if they aren't strictly going against their beliefs. It might be beneficial to talk about the values and direction of the copy desk between the management and copy editors. An 
open dialogue might not create an alignment between the two forces, but it might promote greater understanding. Management might find better ways of managing the desk, and copy editors might be able to see how some of these new tasks are essential to the mission of the organization.

There were also a number of correlations among the factors of satisfaction that would be of merit to think about. First of which, copy editors' satisfaction with the agreement among job expectations was significantly correlated with how satisfied they are with their understanding of their job expectations. So for those who are satisfied with how their responsibilities agree, they are more likely to be satisfied with their understanding of the job (or the reverse). Therefore, addressing either their actual responsibilities or their perceived understanding might influence how satisfied they are with these variables and overall increase how satisfied they are with their position.

However, is it necessary to make adaptations to the copy editing desk as a result of knowing role conflict exists for copy editors? This research indicates that responsibility conflict has a negative impact on how frequently copy editors feel they miss errors because of time constraints and responsibility conflict. However, an even larger indicator is the number of responsibilities, as well as time. Perhaps it would be beneficial to give each editor all of one tasks - and not dividing the same tasks among several people. For instance, perhaps one person a night could be in charge of having social media and website management as their top priorities. This would allow these people to focus solely on these tasks that need to be continuously updated or managed, while allowing others to focus solely on longer, in-depth tasks, which might reduce responsibility conflict. Even if each editor has to do more of one task, they might have 
fewer tasks to be concerned about. For example, a copy editor who no longer handles social media might have more stories to traditionally edit. This might allow them to keep the same mindset, rather than bouncing back and forth between different tasks. Reducing the number of overall tasks each person is responsible for might go a long way toward reducing the number of errors.

Limitations: As one of the few quantitative outlooks on copy editors recently, this thesis is able to provide meaningful numbers that qualitative research cannot. That said, this research did have limitations. One of which was it not able to compensate for how different newsrooms operate. Newsrooms, which once operated in the same general way, have grown apart. The standard workflow has erupted and each newsroom handles copy differently. Some have adapted more quickly to the digital era by adding web teams, while others are making the transition more slowly. The change in operations also means that the same title at different newsrooms often have vastly different meanings and responsibilities. This research was not able to take adapt to all possibilities. This research was also not able to account for all responsibilities copy editors would have, and to avoid user fatigue, therefore limited the possibilities to 13 based on common tasks they might have. However, there could be responsibilities specific to each individual newspaper or even each specific copy editor that this questionnaire did not ask about.

Another limitation was that it did not gauge the intensity of role conflict, but rather asked people how often they felt like their responsibilities conflicted. The conflict could be very bad when it happens, or it could be really easy to deal with. A survey in the future, or even a qualitative study, could try and pinpoint the strength or weakness of the role conflict. It also did not find the frequency of errors overall. 
Further research: A qualitative study could more accurately find the range of tasks a modern copy editor might encounter rather than a pre-determined questionnaire. This approach would also allow for more insight into the emotional strains or gratifications of the job for copy editors. Another survey might also ask about the intensity of role conflict. Research could also be done to determine the frequency of role conflict in other newsroom positions. It could also try and measure the intensity of role conflict - how bad it is when it happens. Research could also be done by asking copy editors more specifically about the mistakes they made, or through more empirical research to find out the number of errors made and the number of errors caught. 


\section{Conclusion}

This research pushed role theory into a new industry and into a modern era, where there are practical applications. Since it is difficult to condense the diverse facets of role conflict into one variable this research examined how role conflict manifests itself in copy editors. For instance, this couldn't measure intensity of role conflict. However, it found there was a prevalent, albeit not overwhelming, frequency of responsibility conflict. The implications can be alarming. Copy editors indicated that half of their errors are a result of responsibility conflict and time constraints. While fundamental problems, these have solutions after understanding them further. There was a direct a link between the number of tasks and the frequency of role conflict. Social media, website management, and page proofing were also highly correlated with the frequency of responsibility conflict. Making simple adjustments to the copy desk workflow might help alleviate these variables. As a result, errors would be reduced and quality would improve.

But this research also found the impact of that role conflict, or the lack thereof, has ties to the emotions of the copy editor: their job satisfaction. Copy editors' overall job satisfaction was most highly correlated with how satisfied their values align with those of the company. Therefore it might be beneficial to have open conversations about why and how those company values developed, and perhaps the company can take the copy editors' value concerns into consideration. This study was able to provide a look, or at least a small glimpse, into challenges and opportunities for the modern copy editor and provide understanding into the workflow. 


\section{Changes from original proposal}

Throughout this thesis process, there were several adaptions between the thesis proposal and the final thesis process. The reason was the researcher learned throughout the thesis process and adapted the thesis in order to make it better.

First, some of the questions on the survey were changed as a result of the pre-test

that was conducted. These are the changes. "To what extent are the following duties part of your job responsibilities?" was changed to "Could you indicate the amount of time and effort you put into each of the following tasks in proportion to the other tasks? If it is not part of your duties, please give it a "None." The question "How much time do you find you spend working with a design center compared to if it was in-house?" was added. The separate satisfaction and dissatisfaction was considered burdensome and redundant by respondents and was changed to one singular question "Could you indicate how each of the following factors contribute to your satisfaction with the job?"

The original sample size was going to be copy editors who work at newspapers with a circulation size of more than 20,000 . This was reduced to 15,000 to increase the sample size.

The collection method also varied slightly. This was the original proposal: Initially, the survey will be delivered through the American Copy Editors Society to its membership who work at newspapers with the specified circulation size and will be encouraged to pass the survey onto colleagues. The respondents will have one week to complete the survey before a reminder email is sent and then one more week to respond. However, if more responses are needed, additional newspapers will be identified through 
the Alliance for Audited Media, and the survey will be directly emailed to the sample through contact information provided in either the Alliance for Audited Media or through the software program Cision, which is frequently used by public relations managers to find contacts at media outlets for press releases. Dorothy Carner at the Missouri School of Journalism Library has granted access to the program to the researcher. Respondents reached through these techniques will also have one week to respond before a reminder email is sent and they will be given another week to respond.

This is what happened as stated in the methods section. It was sent out via email to members of the American Society of Copy Editors. The initial email said the survey was for members who were copy editors at companies that published websites and had a daily circulation of more than 20,000. Additionally, individual emails were sent to executive editors, managing editors or copy desk chiefs at newspapers with a circulation of more than 20,000, and were asked to send the survey on to their copy staff.

After the first week the survey was open, the researcher decided to increase the sample size by decreasing the necessary circulation size to 15,000 . A reminder email was sent to ACES members, with the noted decreased circulation requirement. A new round of emails was sent out to executive editors, managing editors or copy desk chiefs at the new sample size. The researcher looked to identify specific copy editors at newspapers that did not have respondents and worked to contact them directly. The survey was officially open for two weeks. There were a few respondents who responded within a week after it officially closed. Once the survey was closed, multiple linear regressions were run. 
Next, some of the hypotheses and research questions were reordered to provide a more intuitive flow, were rephrased to leave out the controls because those are not necessary to state in the hypothesis unless the controls are among the variables the researcher is specifically looking at. There were also some research questions that were excluded because the researcher did not have the advanced statistical skills necessary to complete them. Some were excluded because the researcher did not realize they would have already been answered by the data in other hypotheses.

Here are the original hypotheses and research questions.

H1: The frequency that copy editors indicate responsibilities conflict for time/attention is positively correlated with the number of tasks copy editors indicate are part of their responsibility and the number of tasks copy editors indicate are high priority. There is also a correlation between the frequency copy editors indicate responsibilities conflict and the types of tasks copy editors indicate take up large portions of their responsibilities. (A hypothesis pertaining to which tasks will impact frequency of conflict cannot be formed).

H2: There are correlations between a copy editor's value of traditional copy editing and tasks copy editors indicate are a high priority, the age of the respondent, the length of time in the industry, how frequently they publish stories online before editing and how frequently they think stories should be published online before editing. (*Notes: There is a positive correlation between value and age, and value and time in industry. There is a negative correlation between value and how frequently they think stories should be posted online. A hypothesis pertaining to the direction of the correlation between value and frequency of publishing cannot be formed.) 
H3: There is a negative correlation between how copy editors prioritize copy editing and the frequency he or she indicates stories can be published online before editing and the frequency they do publish stories before editing.

H4: There is a negative correlation between how copy editors perceive the quality of their traditional copy editing and how frequently they post stories to the Web without editing and how much time they feel they have to complete their tasks.

H5: Role conflict manifests in copy editors through job satisfaction and dissatisfaction.

- H5a: Copy editors indicate they are dissatisfied with their job because of either disagreement with job expectations or difficulty transitioning from one task to another.

- H5b. Copy editors indicate they are satisfied with their job because they work to provide readers with accurate and clear information.

RQ1: Which responsibilities conflict with one another and predict that copy editors will say responsibilities conflict for time and attention?

RQ2: Which responsibilities complement one another and predict that copy editors will say responsibilities do not conflict for time and attention.

RQ3: What is the relationship between the length of time a copy editor has been at his or her organization, how long he or she has been a copy editor, his or her priority of copy editing and his or her value of copy editing?

RQ4: How does the frequency of copy editors publishing stories online and how frequently he or she thinks stories should be published online before copy editing relate? 
RQ5: How does the value copy editors place on traditional copy editing relate to how copy editors prioritize traditional copy editing?

RQ6: Which responsibilities conflict with one another and predict that copy editors say his or her traditional copy editing quality is poor?

RQ7: Which responsibilities complement one another and predict that copy editors say his or her traditional copy editing quality is good?

\section{Here are the final hypotheses:}

Hypothesis 1: Copy editors' satisfaction of how their values align with those of the company is the leading predictor job satisfaction.

Hypothesis 2: Other leading predictors of job satisfaction are those indicative of role conflict or role ambiguity.

Hypothesis 3: How copy editors prioritize copy editing and the frequency he or she indicates stories can be published online predict the frequency they do publish stories online prior to editing.

Hypothesis 4: The respondents' value of traditional copy editing and respondents' opinion of publishing stories before editing has a negative relationship with how frequently stories are published online before editing.

Hypothesis 5: The frequency that copy editors indicate responsibilities conflict for time/attention is positively correlated with the number of tasks copy editors indicate are part of their responsibility and the number of tasks copy editors indicate are high priority.

Hypothesis 6: There is a correlation between the frequency copy editors indicate responsibilities conflict and the types of tasks copy editors indicate take up large portions 
of their responsibilities. (A hypothesis pertaining to which tasks will impact frequency of conflict cannot be formed).

Hypothesis 7: The frequency of responsibility conflict, the number of tasks and the frequency of enough time to complete tasks predict the frequency of errors. 


\section{References}

American Society of News Editors. (2013). Table C- Whites and minorities by job category. Retrieved from

http://asne.org/content.asp?pl=140\&sl=131\&contentid=131

Alexander, J., \& Wall, J. (1975). Righting the wrongs of writing: Copy editors speak out. Personnel \& Guidance Journal, 53(10).

Bell, A. (1991). The Language of News Media. Wiley, John and Sons Incorporated.

Biddle, B. J. (1986). Recent development in role theory. Annual Review of Sociology, $12,67-92$.

Brooks, Brian (2008). Art of editing in the age of convergence. Pearson.

Fidler, E. (2012). A copy desk future? Gateway Journalism Review, 42(326), 7-22.

Hilbert, R. (1981). "Toward an improved understanding of role." Theory and Society. 10(2), 207- 226.

Jarvis, J. Copy Desks Shrinking. Gateway Journalism Review. 42(326), 10.

Keith, S. (2005). Copy editor job satisfaction lowest at small newspapers. Newspaper Research Journal, 26(2), 6-26.

Keith, S. (2005). Newspaper copy editors' perceptions of their ideal and real ethics roles. Journalism and Mass Communication Quarterly, 82(4), 930- 951.

Kemery, E. (2006). Clergy Role Stress and satisfaction: Role ambiguity isn’t always a bad thing. 37.

Klinenberg, E. (2005). Convergence: News production in a digital age. Annals of the American Academy of political and social science, 597, 48-64.

Magee, C. M. (2006). The roles of journalists in online newsrooms. Unpublished manuscript. Medill School of Journalism, Northwestern University, 1-10.

Rizzo, J., House, R., \& Lirtzman, S. (1970). Role conflict and ambiguity in complex organizations. Administrative Science Quarterly, 15(2), 150-163. 
Russial, J. (1998). Goodbye copy desks, hello trouble? Newspaper Research Journal, 39(2), 3 - 17.

Russial, J. (2009). Copy editing not great priority for online stories. Newspaper Research Journal, 30(2), 6 - 15.

Schuler, Randall. (1977) The Effects of Role Perceptions on Employee Satisfaction and Performance Moderated by Employee Ability. Organizational Behavior and Human Performance.

Sessions Stepp, C. (2009). The Quality Control Quandary.

Singer, J. (2006). Stepping back from the Gate: Online Newspaper Editors and the coproduction of content in campaign 2004. Journalism and Mass Communication Quarterly. 86. 265-280.

Smith, V. (1997). New forms of work organization. Annual Review of Sociology, 23, 315-339.

Thatcher, S., \& Zhu, X. (2006). Changing identities in a changing workplace: Identification, identity enactment, self-verification, and telecommuting. The Academy of Management Review, 31(4), 1076-1088.

Tubre, T.C. \& Collins J.M. (2000). Jacks and Schuler (1985) Revisited: A meta-analysis of the relationships between role ambiguity, role conflict, and job performance. Journal of Management. January 2000; 26(1): 155-169.

Turner, R. (1990). Role change. Annual Review of Sociology, 16, 87-110.

Wimmer, R. Dominkick, J. (2011) Mass media research. Australia: Wadsworth Cenage Learnings. 


\section{Appendix}

\section{Recruitment Letter Sent to ACES Members}

\section{Dear (name)}

Missouri School of Journalism graduate student Gwen Girsdansky is currently working on her master's thesis, which examines the responsibilities, values and priorities of copy editors. As part of her research, she is surveying copy editors who work at companies that publish a website and have a newspaper circulation of more than 20,000 . If you fit in this demographic, I invite you to take the survey to help extend knowledge and research about our profession. It should not take more than 20 minutes and can be accessed at this link: https://missouri.qualtrics.com/SE/?SID=SV_25JRpVvVmrzTpUp. The survey will close on Feb. 3. Results will be discussed in a future ACES newsletter.

Thank you for your time,

Fred

Fred Vultee

ACES research coordinator 


\section{Recruitment Letter Sent to Managing Editors}

Dear (name),

My name is Gwen Girsdansky. I'm a graduate student at the Missouri School of

Journalism at the University of Missouri. I'm currently working on my master's thesis, which examines the responsibilities, values and priorities of copy editors at organizations that publish newspapers and websites.

Would you please forward this email on to your copy editors so they have the opportunity to fill out a brief survey that would help me immensely with my research? All responses remain confidential. The survey has not taken most copy editors more than 10 minutes and can be accessed at https://missouri.qualtrics.com/SE/?SID=SV_25JRpVvVmrzTpUp. The survey closes Feb. 3.

Thank you for your time and consideration, Gwen Girsdansky 


\section{Online Questionnaire Sent to Copy Editors}

Q1 This survey is research for a Missouri School of Journalism graduate student's master's thesis on copy editors titled "The Impact of Role Conflict on Copy Editors Who Work at Companies That Produce Newspapers and Websites." The purpose of the thesis is to examine if and how the responsibilities of copy editors conflict, and if and how that has an impact on traditional copy editing.

The paper might be published. Participation is voluntary and anonymous. The survey will ask for the name of your newspaper, but that information is only used to validate demographics and identifying which states respondents are from. It will remain confidential and not included in any paper or presentation. You may skip any question you are uncomfortable answering.

If you wish to terminate participation at any time, please exit the survey. If you have any questions or concerns, please contact the researcher at gwendolyn.girsdansky@gmail.com or the thesis adviser Margaret Walter at waltermr@missouri.edu. By clicking yes, you are giving the researcher consent to use your results. Do you wish to continue with this survey?

O Yes (1)

O No (2)

If No Is Selected, Then Skip To End of Survey

Q2 Could you indicate the amount of time and effort you put into each of the following tasks in proportion to the other tasks? If it is not part of your duties, please give it a "None."

(On a sliding scale of 0 or 'none' and 10 or 'a lot')

Aggregation projects

App updating

Copy editing local stories

Copy editing stories from wire services

Print layout and design

Online photo caption and/or photo gallery editing

Page proof editing

Pulling stories and/or photos from wire

Traditional copy editing (style, grammar, accuracy, gatekeeping)

Website management

Writing/posting social media

Writing print headlines

Writing online headlines 
Q3 How frequently, if ever, do you think that your responsibilities conflict with one another for your time or attention?

(On a sliding scale of 0 or 'never' and 10 or 'all the time')

Q4 How frequently, if ever, do others in the newsroom ask you to complete tasks that are in conflict with your normal responsibilities?

(On a sliding scale of 0 or 'never' and 10 or 'all the time')

Q5 What is the value you place on each of your responsibilities?

(On a sliding scale of 0 or 'none' and 10 or 'a lot')

Aggregation projects

App updating

Copy editing local stories

Copy editing stories from wire services

Print layout and design

Online photo caption and/or photo gallery editing

Page proof editing

Pulling stories and/or photos from wire

Traditional copy editing (style, grammar, accuracy, gatekeeping)

Website management

Writing/posting social media

Writing print headlines

Writing online headlines

Q6 How do you prioritize your responsibilities?

(On a sliding scale of 0 or 'none' and 10 or 'a lot')

Aggregation projects

App updating

Copy editing local stories

Copy editing stories from wire services

Print layout and design

Online photo caption and/or photo gallery editing

Page proof editing

Pulling stories and/or photos from wire

Traditional copy editing (style, grammar, accuracy, gatekeeping)

Website management

Writing/posting social media

Writing print headlines

Writing online headlines

Q7 Do you find that you have enough time to complete your work in a way that meets your personal standards for copy editing?

(On a sliding scale of 0 or 'never' and 10 or 'all the time') 
Q8 On any given shift, how well do you think you are able to complete each of your responsibilities?

(On a sliding scale of 0 or 'very poorly' and 10 or 'very well')

Aggregation projects

App updating

Copy editing local stories

Copy editing stories from wire services

Print layout and design

Online photo caption and/or photo gallery editing

Page proof editing

Pulling stories and/or photos from wire

Traditional copy editing (style, grammar, accuracy, gatekeeping)

Website management

Writing/posting social media

Writing print headlines

Writing online headlines

Q9 How frequently, if ever, do you think you miss errors in stories as a result of time constraints or conflicting responsibilities?

(On a sliding scale of 0 or 'never' and 10 or 'all the time')

Q10 How frequently do you think a story should be published online before it has been traditionally copy edited? (Copy edited for clarity, conciseness, accuracy...etc.)

(On a sliding scale of 0 or 'never' and 10 or 'all the time')

Q11 How frequently do you post stories online before they have been traditionally copy edited?

(On a sliding scale of 0 or 'never' and 10 or 'all the time')

Q12 Is design work completed on site?

O Yes (1)

No (2)

Answer If Is design work completed on site? No Is Selected

Q13 How much time do you find you spend working with a design center compared to if it was in-house?

(On a sliding scale of 0 or 'none' and 10 or 'a lot')

Q14 How satisfied are you with your job?

(On a sliding scale of 0 or 'extremely dissatisfied and 10 or 'extremely satisfied') 
Q15 Could you indicate how each of the following factors contribute to your satisfaction with the job?

(On a sliding scale of 0 or 'extremely dissatisfied and 10 or 'extremely satisfied') Salary Shift hours Co-workers Feeling as if you've done a good job Variety of tasks completed throughout the shifts Work to present accurate and clear information to readers Agreement among job expectations Understanding job expectations Ability to meet expectations Your values match the company's values (

Q16 What is the name of your newspaper organization?

(Fill in the blank)

Q17 What is your job title?

(Fill in the blank)

Q18 How long have held your current job (in years)? (Sliding scale from $0-70$ )

Q19 How long have you held positions in the news media industry (in years)? (Sliding scale from $0-70$ )

Q20 How long have you been a copy editor (in years)?

(Sliding scale from $0-70$ )

Q21 What is your age?

(Fill in the blank)

Q22 What is the highest level of education you have completed?

(Multiple choice)

Less than high school diploma (1)

High school diploma/G.E.D. (2)

O Associate degree (3)

Bachelor's degree (4)

Master's degree (5)

Doctoral degree (6) 
Q23 What is your gender?

(Multiple choice)

O Male (1)

Female (2)

Q24 Are you a part-time or full-time employee?

(Multiple choice)

Part-time (1)

O Full-time (2)

Q25 How much money do you make each year?

(Multiple choice)

Less than $\$ 20,000$ (1)

O $\$ 20,000$ - $\$ 29,999$ (2)

O $\$ 30,000-\$ 39,999$ (3)

O $\$ 40,000$ - $\$ 49,999$ (4)

O $\$ 50,000-\$ 59,999$ (5)

O $\$ 60,000-\$ 69,000$ (6)

O More than $\$ 70,000$ (7) 